\title{
LA PARAFERNALIA PARA CONSUMO DE ALUCINÓGENOS DE "CALLLEGUA" (UUJUY, ARGENTINA): PROCEDENCIA, CRONOLOGÍA Y RELACIONES CIRCUMPUNEÑAS
}

\author{
THE HALLUCINOGENIC PARAPHERNALIA FROM "CALILEGUA" IUJUY, \\ ARGENTINA): PROVENANCE, CHRONOLOGY, AND RELATIONSHIPS IN \\ THE CIRCUMPUNA ANDES
}

AXEL E. NIELSEN ${ }^{A}$

Este trabajo da a conocer una colección arqueológica de la Provincia de Jujuy alojada actualmente en el National Museum of the American Indian, discutiendo su procedencia y relevando su potencial investigativo. Los materiales han sido catalogados en su mayoría como procedentes de Calilegua, pero hay razones para inferir que su verdadera procedencia es la Quebrada de Humahuaca y que son parte de la vasta colección reunida por Karl Schuel entre 1920 y 1923. El estudio de estas piezas puede aportar información valiosa sobre el pasado de la quebrada, en particular sobre los últimos siglos prehispánicos. Tal potencial se ilustra mediante el análisis de tabletas y tubos y sus relaciones con implementos similares de Muyuna y otras partes de los Andes circumpuneños.

Palabras clave: complejo alucinógeno, Calilegua, Quebrada de Humahuaca, Período Medio, Período de Desarrollos Regionales.

This work introduces an archaeological collection from the Province of Jujuy, currently housed in the National Museum of the American Indian, discussing its origin and revealing its research potential. Most materials have been classified as from Calilegua, but there are reasons to infer that their true origin is in the Quebrada de Humahuaca and that they are part of the vast collection gathered by Karl Schuel between 1920 and 1923. The study of these pieces can provide valuable information about the past of the quebrada, particularly from the last pre-Hispanic centuries, as demonstrated by the analysis of snuffing trays and tubes, and their relationships with similar implements from $\mathrm{Mu}$ yuna and other parts of the circum-Puna regions of the Andes.

Keywords: hallucinogenic complex, Calilegua, Quebrada de Humahuaca, Middle Period, Period of Regional Developments.

\section{INTRODUCCIÓN}

En su clásica obra sobre la iconografía de los equipos de inhalar alucinógenos de Sudamérica, Torres (1987) se detiene en una serie de tabletas del Museum of the American Indian de Nueva York que llevan por procedencia Calilegua. Estas piezas llaman su atención porque difieren de las demás conocidas para el Noroeste Argentino (NOA). Varias de ellas poseen, coronando la bandeja, un panel plano de forma rectangular o ligeramente trapezoidal, con su borde superior curvo. La mayoría no tiene decoración, pero una de ellas lleva incisa una imagen femenina con brazos y piernas abiertas (fig. 1). Aunque no se conocen ejemplares comparables en el NOA, las tabletas de esta forma son comunes en San Pedro de Atacama, donde según sus cálculos habría 114 sin decorar y seis con "la Mujer Heráldica", como se conoce el referido ícono. En San Pedro, sin embargo, hay además casi medio centenar de tabletas con apéndice plano y motivos tiwanaku, diseños que se encuentra ausentes en las piezas de Calilegua y en el NOA en general. El autor se abstiene de avanzar sobre el significado de estas relaciones porque, como bien señala, nada se sabe sobre el sitio o los materiales que

A Axel E. Nielsen, CONICET-Instituto Nacional de Antropología y Pensamiento Latinoamericano 3 de Febrero 1378, Buenos Aires, Argentina, email: axelnielsen@gmail.com 
pudieron estar asociados con las tabletas (Torres 1987: 58). A pesar de ello, dadas sus características únicas para la región, estas piezas siguen siendo referenciadas en discusiones sobre cronologías, estilos y significados del complejo alucinógeno en los Andes circumpuneños (Pérez \& Gordillo 1993: 327-328, Torres 1998, Sprovieri 2009, Horta et al. 2016).

Hay razones para pensar que el origen de estos materiales no es Calilegua, ya que los estudios arqueológicos indican que la cuenca del río San Francisco, donde se encuentra esa localidad, estuvo despoblada entre el 500 DC y la invasión europea (Ortiz et al. 2015). La clave de su verdadera procedencia llegó accidentalmente durante una visita al National Museum of the American Indian (Smithsonian Institution, Washington DC, heredero del de Nueva York, en adelante, NMAI) al descubrir que la institución posee también un conjunto inédito de vasijas de estilo Isla Polícromo procedente de Muyuna, un sitio de la Quebrada de Humahuaca que investigamos con nuestro equipo en el año 2000, pero que hasta entonces era conocido solo en la literatura por las reiteradas menciones que de él hiciera Schuel (1929). Al consultar los archivos, fue posible constatar que los materiales de Calilegua y Muyuna habían ingresado juntos al museo como parte de una misma colección que incluye además algunas piezas de otros sitios de esa región. Dichos sitios también fueron excavados por Schuel, como Tilcara, Puerta de Juella y Angosto de Perchel. Esto planteó la posibilidad de que los equipos de inhalar, junto con más de 250 piezas que integran el mismo lote, hubieran sido obtenidos originalmente por él en la Quebrada de Humahuaca, hipótesis que pudo verificarse mediante el estudio de la colección completa.

Los objetivos de este trabajo son, en primer lugar, dilucidar la procedencia y cronología de los materiales atribuidos a Calilegua y otros que forman parte de la colección arqueológica de la Provincia de Jujuy conservada por el NMAI. En segundo lugar, queremos destacar su potencial para el estudio del pasado prehispánico de la Quebrada de Humahuaca, tomando la parafernalia alucinógena como ejemplo. El texto se organiza en seis apartados. Comienza sintetizando lo que se sabe sobre las exploraciones arqueológicas de Schuel en la Quebrada de Humahuaca y el paradero de sus hallazgos. Luego describe la colección del NMAI, expone las razones para concluir que es fruto de su labor e identifica los probables sitos de procedencia de las piezas atribuidas a Calilegua. A continuación, busca establecer el rango temporal de

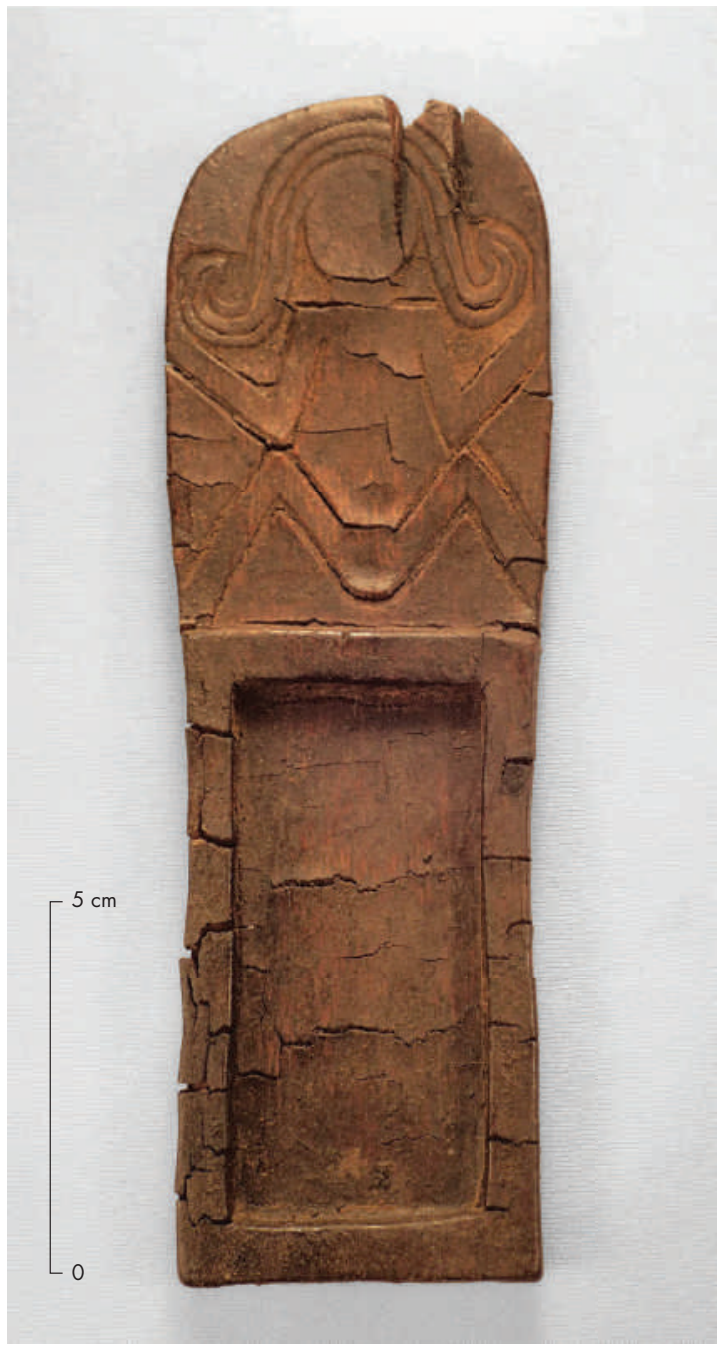

Figura 1. Tableta de apéndice plano con representación de la Mujer Heráldica ( $\left.\mathrm{n}^{\circ} 133657\right)$. Figure 1. Flat-appendix snuffing tray with a figure of the Mujer Heráldica ( $\left.n^{\circ} 133657\right)$.

los materiales, teniendo como referencia el conocimiento actual sobre la cronología prehispánica tardía de la quebrada. Luego describe la parafernalia alucinógena de la colección y, a continuación, presenta resultados de las investigaciones realizadas en Muyuna, donde se encontraron algunos objetos similares en contexto. Para cerrar, discute la cronología de los materiales analizados, relacionándolos con distintos aspectos de la sociedad circumpuneña de comienzos del segundo milenio DC. 


\section{KARL SCHUEL Y SUS LABORES ARQUEOLÓGICAS}

El barón Karl Schuel nació en 1857 en Moravia, a la sazón parte del Imperio Austrohúngaro. Se graduó como ingeniero agrónomo e ingeniero perforador en Viena y en 1906 llegó a la Provincia de Jujuy para desempeñarse como director de la empresa El Petróleo Argentino Ltda. Radicado en la zona de Santa Bárbara, se abocó a exploraciones petroleras por varios años, aparentemente sin mayor éxito económico. Desde su arribo, se interesó también por las investigaciones arqueológicas, botánicas y zoológicas, que se convirtieron progresivamente en su principal ocupación. A raíz de estas inquietudes se vinculó con estudiosos del país como Carlos Bruch, Miguel Lillo y Juan B. Ambrosetti, entre otros. También colaboró con instituciones del país y del extranjero, proveyéndoles de especímenes arqueológicos, botánicos y entomológicos (Ibáñez-Novión 1970, Farro et al. 2012).

En 1919 se mudó a Tilcara. Allí lo conoció Benjamín Muñiz Barreto quien, tras ver las excavaciones que por entonces realizaba en el pukará, lo contrató para dirigir lo que sería la primera expedición por él financiada con el objetivo de reunir piezas arqueológicas del NOA. Esta misión se desarrolló entre agosto de 1919 y enero de 1920 y contó también con la participación del ingeniero austríaco Wladimiro Weiser, quien tuvo la responsabilidad de levantar planos de los sitios trabajados. Hasta fines de noviembre excavaron en distintos lugares de la Quebrada de Humahuaca, trasladándose luego a la Puna, donde exploraron varios sitios en el valle del río Grande de San Juan (Departamento de Santa Catalina). La segunda expedición, entre marzo y octubre de 1920, se concentró en esta última región y estuvo a cargo de Weiser (Balesta \& Zagorodny 2000), aunque Schuel continuó realizando excavaciones para Muñiz Barreto en la quebrada de Humahuaca hasta octubre, por lo menos, según consta en su diario.

Durante estas misiones Schuel mantuvo un diario de campo que, si bien no ofrece mayores detalles sobre los contextos intervenidos, brinda información básica respecto a los sitios excavados -veinte en la Quebrada de Humahuaca, cinco en San Juan Mayo y dos en los Valles- y los materiales encontrados, junto a otras observaciones de interés (Schuel 1919-1920). A medida que avanza la expedición, advierte que algunos yacimientos poseen gran cantidad de ofrendas en las tumbas, incluyendo objetos de oro, por lo que vuelve a ellos con frecuencia. Tal es el caso de Pueblo Juez de Maidana y Puerta de Juella, dos lugares cercanos que por momentos se confunden en las notas. Otros yacimientos, en cambio, resultan muy pobres por lo que son rápidamente abandonados, como ocurre con los principales pukarás de la quebrada.

Tras distanciarse de Muñiz Barreto, Schuel continuó realizando excavaciones en la zona por cuenta propia. Esta parece haber sido la época de mayor dedicación a la arqueología, como lo sugiere la semblanza que de él hacen Mazza y Âlvarez (1929), quienes lo conocieron por aquellos años trabajando solitariamente en el Pukará de Tilcara. Cuentan que vivía cerca de allí, en una "misérrima casucha colgada en las laderas del Guasamayo [entre] el cúmulo de tesoros arqueológicos y de mineralogía y botánica que este hombre talentoso, que por entonces ganaba un jornal de peón, guardaba en su cubil para clasificar primero y luego esparcir generosamente en los institutos públicos, sin más recompensa que la de su satisfacción científica" (Mazza \& Álvarez 1929: 1419). A principios de 1924 el investigador se trasladó a San Salvador de Jujuy para hacerse cargo del Museo Provincial recién creado a instancias suyas, al que se dedicó hasta su muerte en 1927.

Un documento clave para entender las investigaciones realizadas durante su época en Tilcara es un artículo de síntesis, redactado probablemente a poco de mudarse a Jujuy, que fue traducido del alemán por Salvador Mazza y publicado póstumamente por éste (Schuel 1929, ver Mazza \& Álvarez 1929). Lamentablemente, el texto es bastante confuso y, por momentos, contradictorio. Comienza presentando en forma general los sitios refiriéndose a las viviendas, las vías de circulación y las sepulturas, clasificándolas en 10 tipos. Luego describe los hallazgos agrupándolos alternativamente por materia prima (madera, piedra, cerámica, etc.), clase funcional (morteros, platos, hachas, etc.) o actividad (agricultura, vestimenta, religión). Salvo algunas excepciones, no especifica dónde encontró cada cosa, cuestión que limita la utilidad de sus observaciones. Basándose en las características y contenido de las sepulturas, esboza una secuencia de cuatro períodos para la región (primitivo o de la piedra, de los Calchaquíes, de sometimiento por los guerreros de los incas y de la conquista española), aunque no detalla los sitios o tipos de materiales que corresponderían a cada uno. El escrito va acompañado de varias figuras que ilustran toscamente muchos de los materiales encontrados. 
A pesar de las limitaciones señaladas, este informe ofrece datos valiosos para identificar los sitios que excavó después de 1920. Comienza afirmando conocer "40 ruinas" en la quebrada, aunque a lo largo del texto solo nombra $11 .{ }^{1}$ Dos de ellas son el pukará de Tilcara y Puerta de Juella/Juez Maidana, donde trabajó periódicamente durante toda su carrera. Otras cuatro fueron excavadas durante las expediciones de Muñiz Barreto y es improbable que haya vuelto a ellas posteriormente, sea porque en los diarios de campo declara que eran muy "pobres" (Hornillos, Calete, La Cueva) o porque durante las misiones los pobladores locales no autorizaron las excavaciones, como sucedió en Pueblo Viejo cercano a Iturbe (Schuel 1919-1920: 38). Los otros sitios, mencionados solo en este texto, son Muyuna, Chijra, Perchel, Huaco y Coctaca, los que concentraron su labor en aquellos años, además del pukará y Puerta de Juella/ Juez Maidana (fig. 2).

El paradero de los materiales que extrajo Schuel a lo largo de su vida se conoce solo en forma parcial. En 1913 donó al Museum für Völkerkunde de Viena (hoy Weltmuseum) una colección de peces, reptiles y plantas, además de casi 450 especímenes arqueológicos procedentes de Puerta de Juella y del pukará de Tilcara, sitio donde comenzó a excavar a poco de arribar a Jujuy, antes de que lo hicieran Ambrosetti y Debenedetti (Ibáñez-Novión 1970). Los materiales reunidos durante las expediciones patrocinadas por Muñiz Barreto forman parte de la colección homónima conservada en el Museo de La Plata. En ella están incluidos también algunos objetos encontrados por Schuel posteriormente, como los vinculados al trabajo lapidario en el pukará (Schuel 1929: 1440), descritos luego por Krapovickas (1961). Es probable que gran parte de la colección reunida por el investigador durante aquellos años en Tilcara haya pasado al Museo Provincial, pero es difícil saberlo, ya que esos materiales se dispersaron tras su muerte. Algunos fueron a dar al Museo Histórico Provincial y eventualmente pasaron a formar parte de la colección del Museo Carlos Darwin del Colegio Nacional T. Sánchez de Bustamante de San Salvador de Jujuy (Ibáñez-Novión 1970).

\section{LAS COLECCIONES ARQUEOLÓGICAS DE JUJUY EN EL NMAI Y SU PROCEDENCIA}

El NMAI fue creado en 1990 a partir de la transferencia de los materiales del Museum of the American Indian

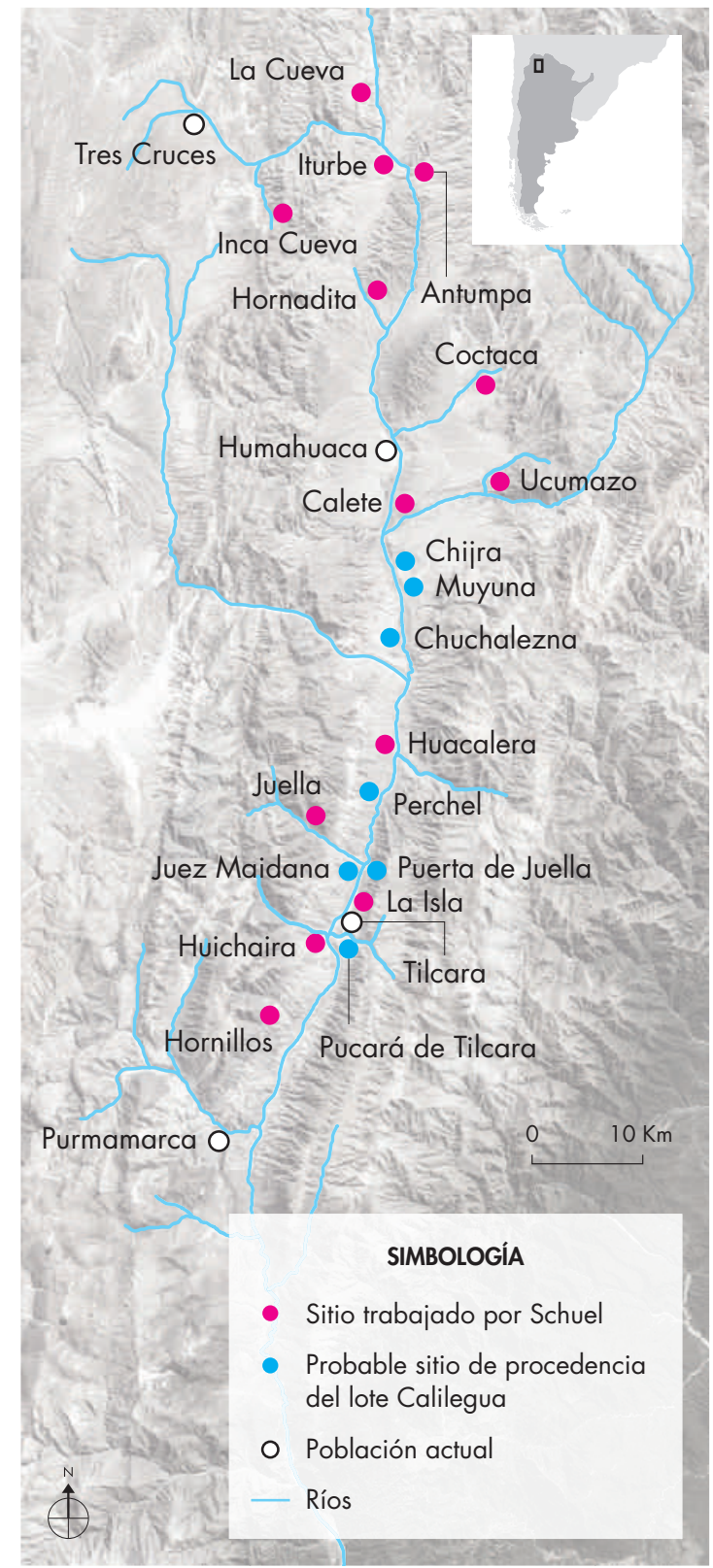

Figura 2. Sitios excavados por Schuel en la Quebrada de Humahuaca. Figure 2. Sites excavated by Schuel in Quebrada de Humahuaca.

de Nueva York -fundado por George G. Heye en 1916a la Smithsonian Institution. Entre sus colecciones se encuentran varios centenares de objetos procedentes de la Provincia de Jujuy correspondientes a dos conjuntos obtenidos de modo diferente. El primero ingresó en 1922 fruto de un intercambio con el Museo Etnográfico de Buenos Aires -hoy Museo Etnográfico Juan B. 
Tabla 1. Objetos adquiridos por el intercambio con el Museo Etnográfico de Buenos Aires. Table 1. Objects acquired by exchange with the Museo Etnográfico de Buenos Aires.

\begin{tabular}{|c|c|c|c|c|c|c|c|c|}
\hline MATERIAL & ARTEFACTO & $\begin{array}{l}\text { PUKARÁ DE } \\
\text { TILCARA }\end{array}$ & $\begin{array}{l}\text { PUKARÁ DE } \\
\text { YAKORAITE }\end{array}$ & LA HUERTA & $\begin{array}{c}\text { LOS } \\
\text { AMARILLOS }\end{array}$ & LA ISLA & HUACALERA & TOTAL \\
\hline Cerámica & Vasija & 26 & 2 & 4 & 2 & 7 & 5 & 46 \\
\hline \multirow[t]{4}{*}{ Piedra } & Mortero & 2 & 1 & & & & & 3 \\
\hline & Mano & 5 & & & & & & 5 \\
\hline & Martillo & 3 & & & & & & 3 \\
\hline & $\begin{array}{l}\text { Punta de } \\
\text { proyectil }\end{array}$ & 1 & & & & & & 1 \\
\hline \multirow[t]{3}{*}{ Hueso } & Tubo & $4(12)^{*}$ & & & & & & $4(12)$ \\
\hline & $\begin{array}{c}\text { Instrumento } \\
\text { para tejer }\end{array}$ & $2(8)^{*}$ & 1 & & & & & $3(9)$ \\
\hline & Espátula & $1^{*}$ & & & & & & 1 \\
\hline \multicolumn{2}{|c|}{ Total } & $44(58)$ & 4 & 4 & 2 & 7 & 5 & $66(80)$ \\
\hline
\end{tabular}

* Los números corresponden a la cantidad de entradas en el catálogo; números en paréntesis corresponden a la cantidad de objetos cuando varios de ellos han sido agrupados en una misma entrada.

Ambrosetti- y comprende 80 objetos, catalogados en 66 números de inventario, ${ }^{2}$ (tabla 1 ) procedentes del pukará de Tilcara, Los Amarillos, La Huerta, Yakoraite, La Isla y Huacalera. Estos materiales fueron entregados por Salvador Debenedetti, director de la institución en ese momento, y probablemente fueron parte de los conjuntos extraídos por él y Ambrosetti durante las expediciones a la quebrada organizadas por la Facultad de Filosofía y Letras de la Universidad de Buenos Aires (Debenedetti 1910, 1918; Ambrosetti 1912). En su mayoría son vasijas cerámicas, pero incluye también artefactos de piedra y hueso.

El segundo lote comprende 320 números de inventario y fue "presentado" en 1924 por Harmon Hendricks, un colaborador de Heye (Annual Report 1925: 7). Los archivos de la institución no incluyen documentación sobre las circunstancias en que se obtuvieron, pero ciertos indicios permiten suponer que fueron comprados a intermediarios en Buenos Aires. En la mayoría de los casos la procedencia señalada es Calilegua, ciudad ubicada en los valles orientales de Jujuy, Departamento de Ledesma, mientras que el resto provendría de distintos lugares de la Quebrada de Humahuaca, como Moyuna (actualmente conocido como Muyuna), Tilcara, Puerta de Juella de Manano (Juez Maidana), Huero, Abra (Angosto) de Perchel y Chucalezna (tabla 2).

Que Calilegua sea el lugar de procedencia del primer grupo resulta dudoso, entre otras razones porque el $20 \%$ de los objetos son de madera, material que se conserva difícilmente en el ambiente cálido y húmedo de la zona donde se encuentra esa localidad. Por otra parte, las piezas de ese lote, como el resto de la colección, son comparables a materiales que se atribuyen a distintos períodos de la era prehispánica tardía de la Quebrada de Humahuaca (ca. 1000-1600 DC). La intervención de Schuel en la obtención de estos materiales está insinuada no solo porque los demás sitios listados en el catálogo son mencionados en su artículo, con la excepción de Chucalezna (Schuel 1929), sino porque dos de ellos, Muyuna y Huero, no cuentan con otras referencias en la literatura arqueológica, lo que indica que no fueron explorados por otros investigadores. Estos indicios llevaron a pensar que fue Schuel quien extrajo todas estas piezas en la 
Tabla 2. Objetos ingresados por H. Hendricks en 1924. Table 2. Objects incorporated in the collection by H. Hendricks in 1924.

\begin{tabular}{|c|c|c|c|c|c|}
\hline MATERIAL & ARTEFACTO & CALILEGUA & MUYUNA & OTROS SITIOS* & TOTAL \\
\hline Cerámica & Vasija & 115 & 45 & 12 & 172 \\
\hline \multirow[t]{3}{*}{ Piedra } & Recipiente & 3 & 2 & & 5 \\
\hline & Tortero & 1 & & & 1 \\
\hline & Cuenta & 13 lots & & & 13 lots \\
\hline \multirow[t]{2}{*}{ Oro } & Anillo & 1 & $1(\mathrm{Au}-\mathrm{Ag})$ & & 2 \\
\hline & Ornamento & 3 & & & 3 \\
\hline Plata & Ornamento & 2 & & & 2 \\
\hline \multirow[t]{7}{*}{ Cobre/bronce } & Campanita & $5(11)$ & & & $5(11)$ \\
\hline & Topo & 3 & & & 3 \\
\hline & Alambre & 1 & & & 1 \\
\hline & Cincel o formón & $4(12)$ & & & $4(12)$ \\
\hline & Tumi & 1 & & & 1 \\
\hline & Brazal & 1 & & & 1 \\
\hline & Otros & $2(3)$ & & & $2(3)$ \\
\hline \multirow[t]{7}{*}{ Hueso } & Tortero & $1(2)$ & & & $1(2)$ \\
\hline & Instrumento para tejer & $11(19)$ & & & $11(19)$ \\
\hline & Tubo & $4(36)$ & & & $4(36)$ \\
\hline & Espátula-cucharita & $6(7)$ & & & $6(7)$ \\
\hline & Asta & 1 & & & 1 \\
\hline & Punta de proyectil & 2 & & & 2 \\
\hline & Otros & 2 & & & 2 \\
\hline \multirow[t]{2}{*}{ Concha } & Cuentas & 2 lots & & & 2 lots \\
\hline & Disco & 1 & & & 1 \\
\hline Fibra animal & Tejido & 1 & & & 1 \\
\hline Fibra vegetal & Fragmentos de soga & 1 & & & 1 \\
\hline \multirow[t]{14}{*}{ Madera } & Campana & 2 & & & 2 \\
\hline & Horqueta o "tarabita" & 2 & & & 2 \\
\hline & Tableta de inhalar & 13 & & & 13 \\
\hline & Tubo de inhalar & $7(10)$ & & & $7(10)$ \\
\hline & Espátula-cucharita & 5 & & & 5 \\
\hline & "Vasitos" & $2(6)$ & & & $2(6)$ \\
\hline & Figurina & 1 & & & 1 \\
\hline & Tortero & $3(4)$ & & & $3(4)$ \\
\hline & Instrumento para tejer & 3 & & & 3 \\
\hline & Pala & 5 & & & 5 \\
\hline & Cascabel de nuez & $2(7)$ & & & $2(7)$ \\
\hline & "Manopla" & 1 & & & 1 \\
\hline & Aguja & 1 & & & 1 \\
\hline & Otros & $8(9)$ & & & $8(9)$ \\
\hline \multicolumn{2}{|c|}{ Total } & $260(331)$ & 48 & 12 & 32091) \\
\hline
\end{tabular}

* Los otros sitios mencionados son Puerta de Juella o Pueblo Juez de Maidana ("Puerta Juella Manano" 2 ítems), Chucalezna (1), Huaco ("Huero" 1), Abra de Perchel (5) y Tilcara (3). 


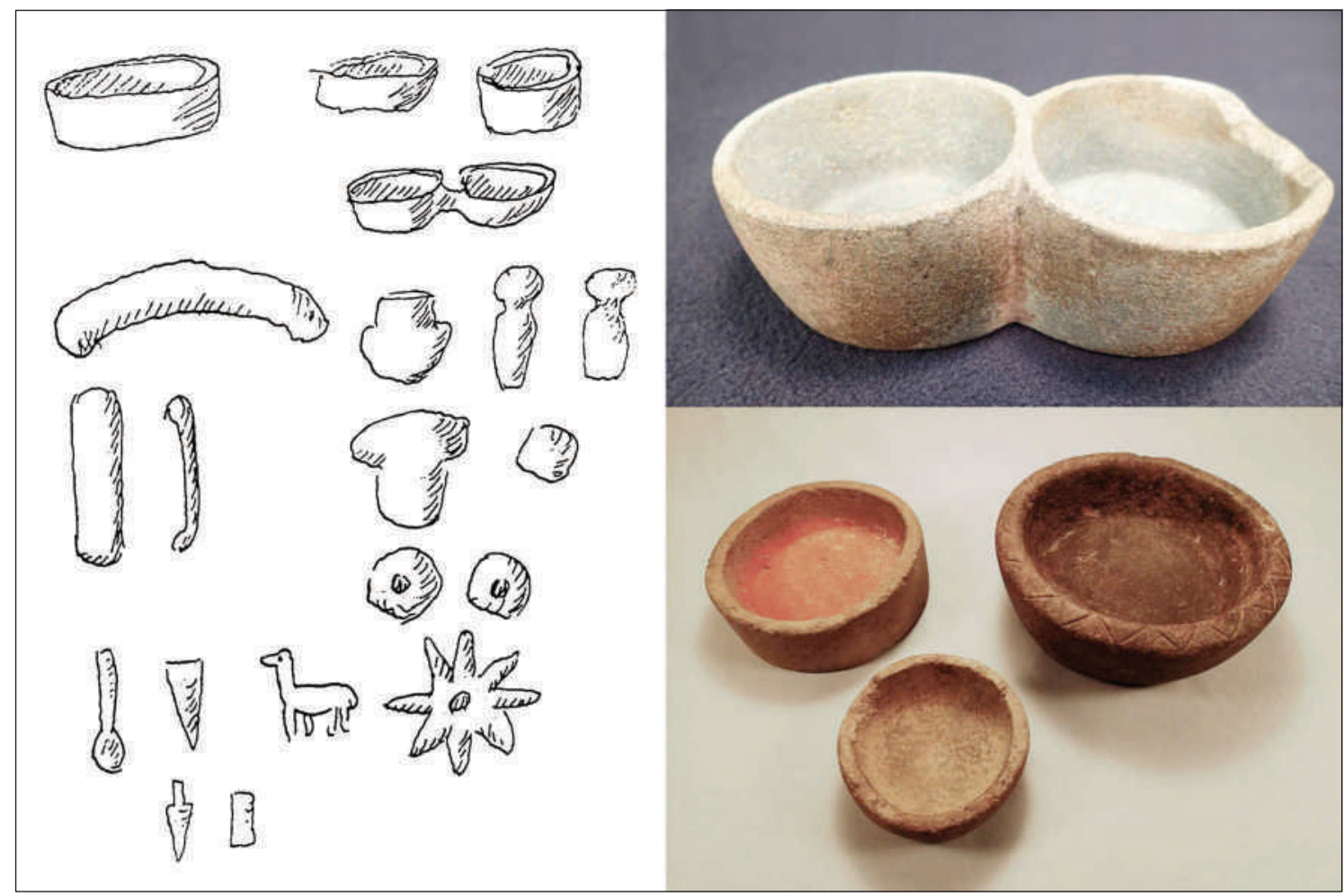

Figura 3. Cuencos de piedra del NMAI identificables en Schuel (1929: fig. 2). Figure 3. NMAI stone bowls identifiable in Schuel (1929: fig. 2).

quebrada, tal vez de los mismos sitios que aún figuran en el catálogo del NMAI, pero que la procedencia de la mayoría de ellas se extravió durante su donación o venta. Que este desafortunado accidente haya afectado a casi todos los materiales no cerámicos -seguramente, embalados por separado- sugiere que ocurrió durante el envío, el que debió involucrar además intermediarios entre Schuel y Hendricks. En tal caso, Calilegua podría ser solo la ciudad donde se realizó la transacción, lo que parece probable teniendo en cuenta que Schuel vivió muchos años cerca de esa localidad y debía tener contactos en la zona.

Estas sospechas se vieron confirmadas al identificar en la colección varios artefactos correspondientes fehacientemente a especímenes que Schuel describe y/o ilustra en su trabajo. Los dos primeros son objetos catalogados como procedentes de Muyuna, uno de los sitios que menciona con mayor frecuencia en el artículo y que figura como procedencia de la mayoría de las demás piezas de la colección (tabla 2). Schuel propone este sitio como ejemplo del primer momento de su secuencia, al que denomina "período de la piedra", ya que "en casi todas las sepulturas encontré adornos de oro, en su mayoría anillos y además objetos de oro laminado. Había además muchas azadas de piedra, platitos de piedra muy bien hechos y utensillos de madera, en su mayoría podridos" (Schuel 1929: 1435, destacado nuestro). Cuatro de estos platitos se ilustran en la figura que acompaña el texto. El NMAI posee cinco de estos objetos, tres atribuidos a Calilegua y dos a Muyuna, incluyendo un ejemplar doble ( $n^{\circ} 133597$, fig. 3 ), posiblemente el dibujado en la publicación.

En la siguiente página de su publicación, Schuel ilustra uno de los anillos confeccionado en oro y plata, el que describe así: "[m] uy interesante era un anillos [sic] que encontré en Moyuna; lo formaba una cinta de oro de $1 \mathrm{ctm}$. de ancho, arrollada y que llevaba soldado un disco de $21 / 2 \ldots$. Sobre el disco había una cruz de oro superpuesta" (Schuel 1929: 1447). Indudablemente se trata del ejemplar $n^{\circ} 133618$ (fig. 4a). Las otras cuatro piezas de oro en la colección del NMAI llevan Calilegua por procedencia, pero una claramente no es de allí $\left(\mathrm{n}^{\circ} 133622\right.$, fig. $\left.4 \mathrm{~b}\right)$, como indica el siguiente pasaje: “También encontré un pendiente en Moyuna; era de 
$11 / 2$ ctms. de ancho y de alto y llevaba en ambos lados un adorno semicircular y arriba un agujero para recibir el cordón" (Schuel 1929: 1445). Esto demuestra que algunas de las piezas del "lote Calilegua" también provienen de Muyuna y, tal vez, de algunos de los otros sitios registrados en el catálogo.

En la siguiente figura del documento, el autor presenta los artefactos de madera. Al menos tres de ellos son reconocibles en el lote Calilegua del NMAI. El primero es una tableta con tres apéndices tallados al bulto -dos antropomorfos y un ave al centro (fig. 5a)que se encuentra entre las publicadas por Torres (1987, Plate 146). Otro es un ejemplar de lo que en el noroeste argentino se conoce como "manopla" (fig. 5b), aunque todavía no haya podido clarificarse la función de estos objetos. Curiosamente, Schuel se refiere a él como un "imperdible" - un alfiler de gancho- "que llevaba en el borde superior 4 quirquinchos, el de atrás tenía la cola del precedente en la boca y el imperdible estaba muy bien conservado" (Schuel 1929: 1442). El tercero es un aerófono de tres tubos con orificio de suspensión (fig. $5 c)$ que el autor describe del siguiente modo: "[u]na flauta tritonal de Chijra tenía $10 \mathrm{ctms}$. de largo por 3 de ancha [sic] y poseía tres agujeros; perforada longitudinalmente y aplanada, estabo [sic] perforada por dos agujeros en el extremo inferior para recibir un cordón" (Schuel 1929: 1443). Chijra es otro de los sitios donde el investigador parece haber trabajado intensamente, ya que lo cita reiteradamente, aunque no figura como procedencia en los catálogos del NMAI. Allí encontró algunos elementos de indudable filiación inca, como "un rompecabeza de cobre [...] con 8 picos y [...] un agujero en el medio para recibir el mango" (Schuel 1929: 1444). El sitio es un pequeño conglomerado ubicado en la margen izquierda del río Grande de Humahuaca, $1 \mathrm{~km}$ al norte de Muyuna. Aunque no ha vuelto a ser investigado, los indicios arquitectónicos y cerámicos superficiales ratifican su antigüedad inka, aunque el inicio de su ocupación podría remontarse al período inmediatamente anterior.

Otra pieza reconocible en el lote Calilegua ( ${ }^{\circ}$ 133615) no se ilustra, pero se describe en detalle: "Un brazal de cobre, procedente de Perchel era de $10 \mathrm{ctms}$. de largo y algo espesado en ambos extremos [...] En ambos extremos era excavada esta pieza y ambos lados longitudinales arqueados un ctm., en ángulo recto; poseía agujeros para el pasaje de un cordón y era llevada del lado externo de la pierna" (Schuel 1929: 1444). Este

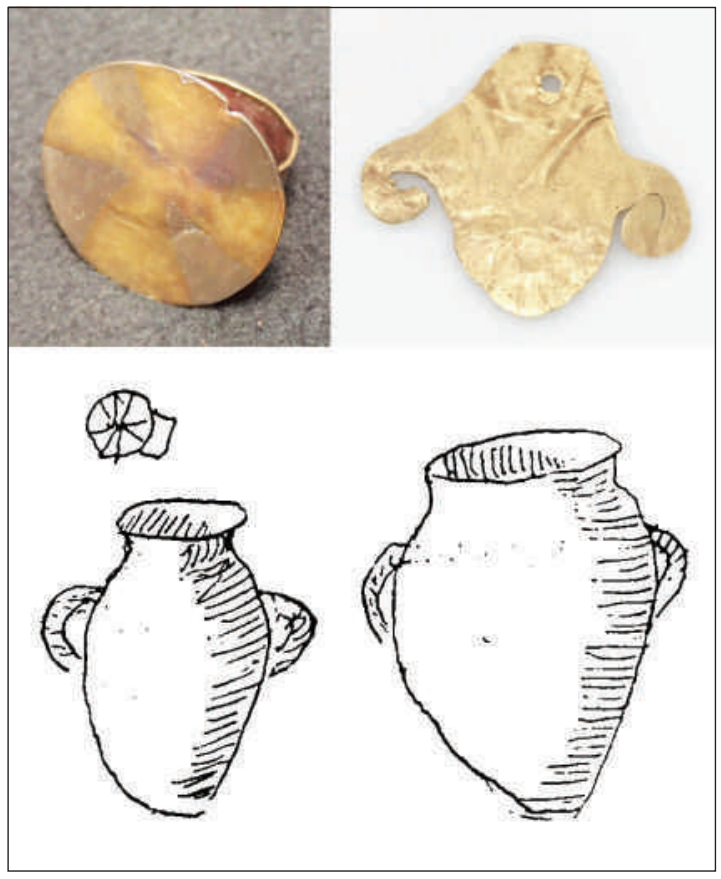

Figura 4. Piezas de oro procedentes de Muyuna: a) anillo bimetálico ilustrado en Schuel (1929: fig. 3); b) colgante. Figure 4. Pieces of gold from Muyuna: a) bimetallic ring illustrated in Schuel (1929: fig. 3); b) pendant.

tipo de brazales tiene una amplia dispersión geográfica y temporal. Se los encuentra en distintas regiones del NOA, norte de Chile y sur de Bolivia, en contextos que van desde mediados del primer milenio DC hasta la época inka (Mayer 1986; Lechtman et al. 2010).

De lo expuesto se puede concluir que la colección de Jujuy presentada por Hendricks en enero de 1924 fue reunida originalmente por Schuel en sitios de la Quebrada de Humahuaca, probablemente después de su alejamiento de Muñiz Barreto, es decir, entre fines de 1920 y 1923. La procedencia de la mayoría de los objetos se extravió durante la donación (o venta) y fue reemplazada por Calilegua en los inventarios, lo que sugiere que esta transacción se realizó en dicha localidad o involucró intermediarios de la zona. Los materiales así catalogados son de sitios distintos y de diversa cronología, incluyendo el Período Hispano-Indígena. Este último se encuentra representado por una punta de hueso de base escotada ( $\mathrm{n}^{\circ} 133582$ ), instrumento característico de esa época en la quebrada y en otras partes del noroeste argentino (Rivolta \& Nielsen 1998, Hernández Llosas 2000: 194). 


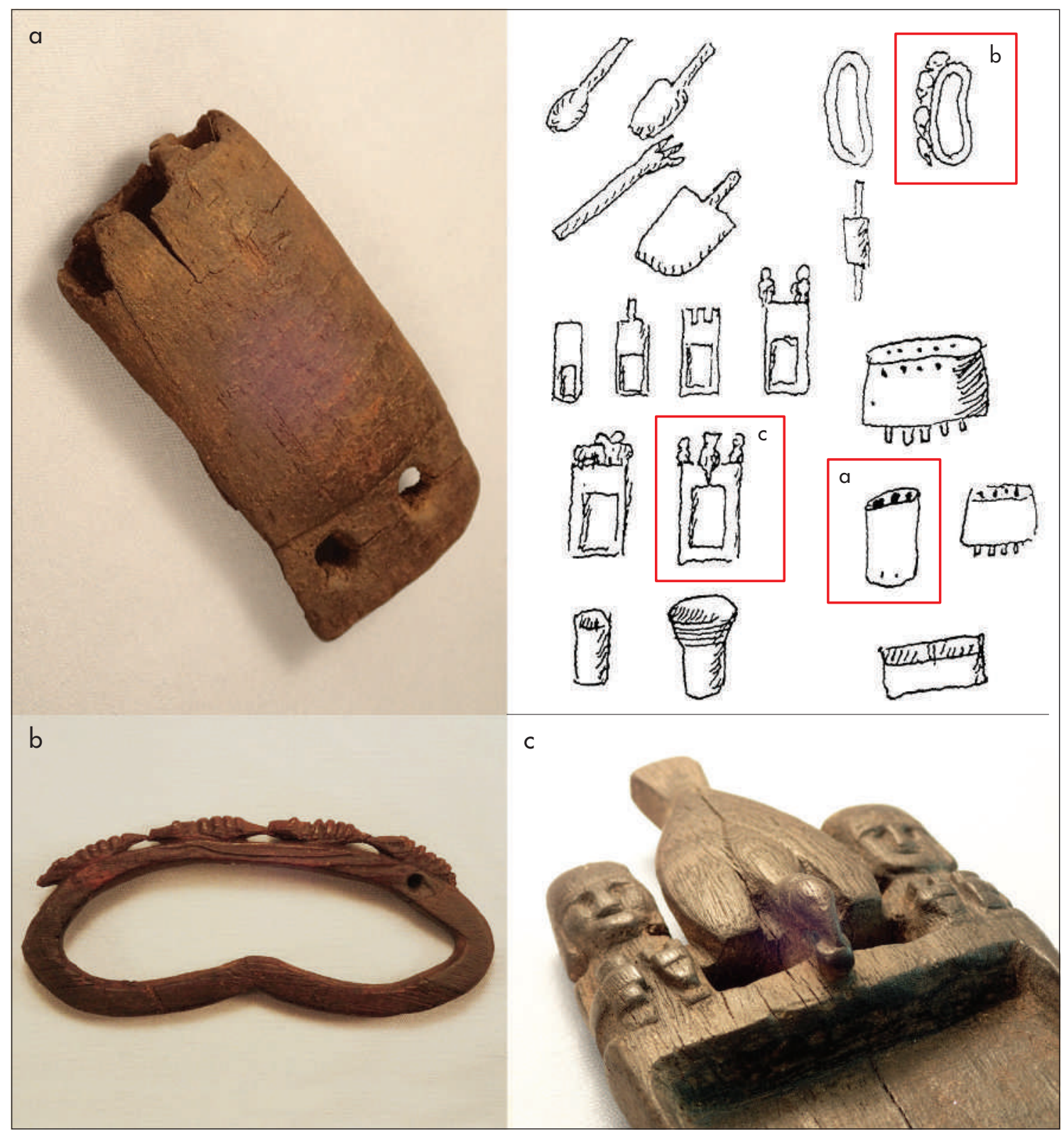

Figura 5. Algunas piezas de madera identificables en Schuel (1929: fig. 4). Figure 5. Some wooden pieces identifiable in Schuel (1929: fig. 4).

Los sitios de procedencia identificados con seguridad hasta aquí para el lote Calilegua serían $\mathrm{Mu}-$ yuna, Chijra y Perchel. A ellos cabe agregar el pukará de Tilcara, donde Schuel excavó regularmente en aquellos años y que podría ser el origen de los objetos hispano-indígenas, ya que cuenta con claros indicios de ocupación durante ese período (Zaburlín 2009). Considerando que tres de ellos (Muyuna, Perchel y
Tilcara) se encuentran entre los lugares de procedencia de la colección que no fueron extraviados, cabe pensar que los demás sitios de esa nómina (Puerta de Juella/ Juez Maidana, Huero y Chucalezna) también pudieron aportar materiales a este lote. Que Schuel retornara al primero de ellos es comprensible, ya que había excavado allí con anterioridad y fue el yacimiento más pródigo de los trabajados bajo el patrocinio de Muñiz 
Barreto. "Huero" o "Huaco", como figura en la publicación, es también un buen candidato, ya que encontró allí varias piezas de oro, incluyendo una campanilla, un disco circular y una máscara (Schuel 1929: 1445). Chucalezna, en cambio, no se menciona en los diarios ni en la publicación. Se lo conoce como un sitio pequeño ocupado a fines del siglo XIII, probablemente durante un lapso relativamente breve a juzgar por la escasez de desechos que muestra en superficie y en los sondeos realizados (Nielsen 2001: 201). Si se trata del mismo lugar, difícilmente Schuel haya obtenido en él materiales en cantidad, aunque también podría tratarse de otro sitio en esa localidad cuya ubicación exacta no se conoce actualmente. La última posibilidad es Coctaca, que se menciona en 1929 pero no en los diarios de la expedición Barreto, por lo que probablemente fue visitado en la misma época. No obstante, este sitio puede descartarse ya que, según informa, las sepulturas allí excavadas carecían de acompañamiento (Schuel 1929: 1433).

\section{Cronología de la Colección}

Las evidencias disponibles actualmente permiten reconocer un mínimo de seis períodos para la época agroalfarera anterior a 1600 DC en la Quebrada de Humahuaca (tabla 3). Dentro de este dilatado lapso, solo los últimos seis o siete siglos han podido ser investigados con cierto detalle, porque la intensa actividad geomorfológica que afecta el valle ha arrasado o sepultado la mayor parte de los rastros arqueológicos anteriores. Por ello, mientras el registro de los sectores altos de la cuenca del río Grande o la puna adyacente, geológicamente más estables y con oferta de abrigos rocosos, da cuenta de una ocupación sostenida de la región durante los últimos diez milenios (Aschero 2000a), en el valle principal no se conocen sitios anteriores al comienzo de la era y los contextos del primer milenio DC son escasos. En su mayoría han sido descubiertos accidentalmente, tal como lo ejemplifican los rescates en el área urbana de Tilcara (Otero \& Rivolta 2015).

Tabla 3. Modelo cronológico para la Quebrada de Humahuaca (época agroalfarera). Table 3. Chronological model for the Quebrada de Humahuaca (Agro-ceramic Period).

\begin{tabular}{|c|c|c|c|}
\hline Años DC & PERIOODO & COMPONENTE & GRUPOS CERÁMICOS \\
\hline ¿500? & $\begin{array}{c}\text { Formativo } \\
\text { temprano \& medio }\end{array}$ & $?$ & Arasayal; San Francisco \\
\hline $900 / 1000$ & $\begin{array}{c}\text { Formativo tardío } \\
\text { Temprano (Pérez 1973) }\end{array}$ & $\begin{array}{l}\text { AA - Alfarcito Antiguo } \\
\text { Agroalfarero Antiguo } \\
\text { (Madrazo 1969) }\end{array}$ & $\begin{array}{l}\text { Alfarcito Bicolor; Alfarcito } \\
\text { Gris Pulido; Negro Pulido }\end{array}$ \\
\hline 1250 & $\begin{array}{c}\text { Desarrollos Regionales I } \\
\text { Medio (Pérez 1973) }\end{array}$ & $\begin{array}{l}\text { IAP - Isla/Alfarcito } \\
\text { Cultura Media } \\
\text { (Bennett et al. 1948) }\end{array}$ & $\begin{array}{l}\text { Peñas Coloradas; Isla Bicolor } \\
\text { \& Polícromo; Alfarcito } \\
\text { Polícromo; Int. Negro Pulido; } \\
\text { Grabado }\end{array}$ \\
\hline 1430 & $\begin{array}{c}\text { Desarrollos Regionales II } \\
\text { Tardío (Pérez 1973) }\end{array}$ & $\begin{array}{l}\text { HUM - Humahuaca } \\
\text { Cultura Humahuaca } \\
\text { (Bennett et al. 1948) }\end{array}$ & $\begin{array}{l}\text { Sarahuaico; Tilcara N/R; } \\
\text { Juella Polícromo; Poma N/R; } \\
\text { Angosto Chico Inciso; Int. } \\
\text { Negro Pulido }\end{array}$ \\
\hline 1536 & Inka & INKA - Inka & $\begin{array}{l}\text { + Humahuaca-Inka; Inka } \\
\text { Imperial; Inka Provinciales } \\
\text { (Inka Pacajes, Inka Paya) }\end{array}$ \\
\hline 1600 & Hispano-Indígena & $?$ & $?$ \\
\hline
\end{tabular}




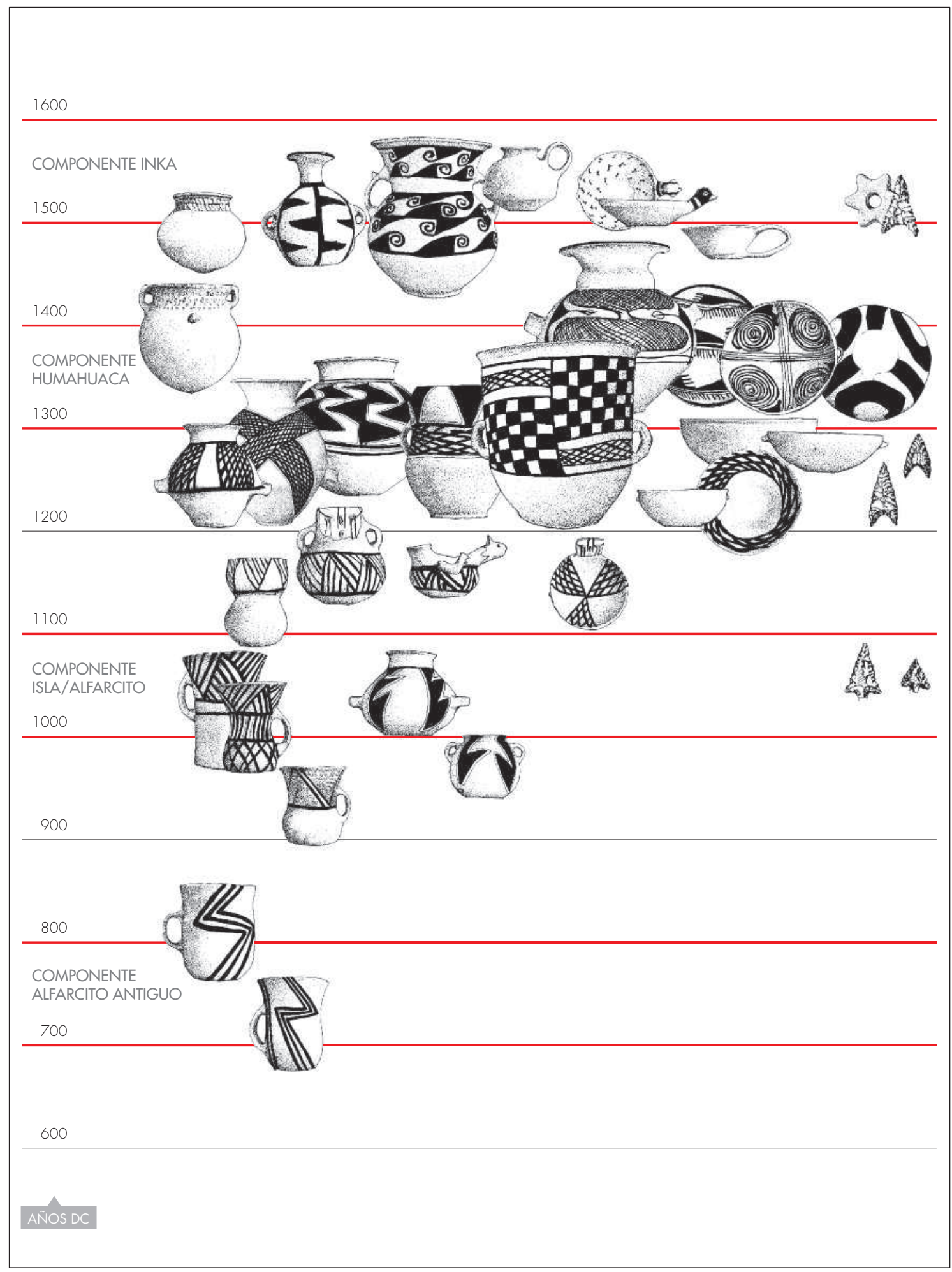

Figura 6. Cronología de la alfarería decorada de la Quebrada de Humahuaca (600-1600 DC). Figure 6. Chronology of decorated pottery from Quebrada de Humahuaca (600-1600 DC). 
Acotando el análisis al último milenio del pasado prehispánico y tomando como indicador la cerámica decorada, un material ubicuo que ha demostrado ser sensible a los cambios temporales en la zona, se distinguen cuatro componentes alfareros sucesivos: Alfarcito Antiguo (AA), Isla/Alfarcito (IAP), Humahuaca Negro sobre Rojo (HUM) e Inka (fig. 6). Este esquema ofrece un marco de referencia útil para estimar la posición cronológica de la colección, aunque requiere algunas aclaraciones.

Lo más controvertido de esta secuencia es la antigüedad de los componentes AA, representado por el "contexto agroalfarero antiguo" definido por primera vez en Alfarcito (Madrazo 1969), y IAP, correspondiente a los estilos Isla y Alfarcito Polícromos (Bennett et al. 1948) y grupos relacionados (p. ej. Peñas Coloradas, Interior Negro Pulido, etc.). Antes de la existencia de dataciones radiocarbónicas, este último componente había sido postulado como una manifestación local de la expansión de Tiwanaku en el centro-sur andino, atribuyéndolo a un Período Medio tentativamente ubicado entre 700 y 1000 DC (Pérez 1973). ${ }^{3}$ Dicha hipótesis parecía avalada por el hallazgo de vasos de estilo Isla Polícromo asociados con cerámica San Pedro Negra Pulida y otros materiales de filiación Tiwanaku en tumbas de San Pedro de Atacama, lo que además señalaba a este oasis como un nexo importante en la llegada de aquellas influencias a la quebrada (Tarragó 1977). Esta interpretación, sin embargo, se vio refutada en la década de 1990 cuando la acumulación de dataciones absolutas reveló que el componente Isla/Alfarcito se ubica en realidad a principios del segundo milenio, mientras AA ocupa los últimos siglos del primero (Nielsen 2001). Cabe señalar que este modelo también encuentra eco en el registro funerario de San Pedro de Atacama, donde los vasos del estilo Alfarcito Bicolor (sensu Madrazo 1969, cf. Tarragó 1989: fig. 24) son relativamente frecuentes durante la Fase Coyo (Berenguer et al. 1986). Tampoco es incompatible con las asociaciones de las piezas Isla Polícromo en ese oasis. Aunque no han podido ser datadas, estas últimas deberían ubicarse, de acuerdo al esquema actual, a fines del siglo x o comienzos del XI, momento de transición entre AA y IAP en la quebrada.

Un análisis estadístico realizado sobre las 68 fechas radiocarbónicas publicadas hacia 2005 para las que pudo establecerse asociación con alguno de los cuatro componentes referido mostró que la transición entre AA y IAP tuvo lugar alrededor del 1000 DC, entre IAP y
HUM a mediados del siglo XIII, y que Inka se incorpora a comienzos del siglo $\mathrm{xv}$, sin desplazar a la mayoría de los grupos característicos de HUM, que continúan en vigencia (tabla 3 , ver detalles en Nielsen 2007). Tomando en consideración estos resultados y las periodizaciones más difundidas en el NOA, que sitúan el final del Período Agroalfarero Medio (González \& Pérez 1972) o Formativo (Núñez Regueiro 1974) entre el 900 y 1000 DC, el "Período Medio" de la quebrada fue redefinido como Desarrollos Regionales Tempranos (PDR I). Más allá de las denominaciones, esta propuesta invita a pensar los fenómenos sociales asociados al componente IAP en relación con agencias y procesos locales y en un contexto de interacciones fundamentalmente circumpuneñas, más que como consecuencia periférica de políticas orquestadas desde Tiwanaku (Nielsen 2001, 2007). Es preciso enfatizar que esto no equivale rechazar a priori la existencia de influencias de esa formación política altiplánica sobre la quebrada a fines del primer milenio, pero significa que las evidencias de esas interacciones deben buscarse principalmente en sitios asociados al componente alfarero AA de los que, desafortunadamente, no se sabe casi nada.

Lo primero que revela el examen de la cerámica jujeña del NMAI es la ausencia total de vasijas del componente AA $o$ anteriores. Tampoco hay otros materiales que puedan atribuirse a momentos tempranos, lo que permite concluir que la colección entera dataría del lapso comprendido entre 1000 y 1600 DC, aproximadamente. Esto es consistente con lo que se sabe de la cronología de los sitios de procedencia identificados en el apartado anterior, cuyos períodos probables de ocupación se indican en la tabla 4. Resumiendo lo expuesto hasta aquí, Muyuna sería el principal lugar de origen de los materiales del lote Calilegua correspondientes al PDR I, seguido tal vez por Puerta de Juella/Juez Maidana y Huaco (sitio hasta hoy desconocido), mientras que los del PDR II, Inka e Hispano-Indígena serían principalmente del pukará de Tilcara, Chijra y Perchel, quizás con algún aporte de Chucalezna.

Antes de poner el foco en los implementos del complejo alucinógeno en la colección, conviene comentar la ubicación de este tipo de materiales en la actual cronología regional. Como sostienen varios autores (Torres 1998, Sprovieri 2009, Horta 2012), la parafernalia de inhalar conocida para el NOA dataría de épocas posteriores al 900 o 1000 DC. Para la Quebrada de Humahuaca, específicamente, la mayoría de las tabletas y tubos conocidos 
Tabla 4. Probables sitios de procedencia de los materiales del lote Calilegua. Table 4. Probable sites of origin of the materials in the Calilegua lot.

\begin{tabular}{|c|c|c|c|c|c|}
\hline \multirow{2}{*}{ SITIO } & \multirow{2}{*}{ REFERENCIA } & \multicolumn{4}{|c|}{ PERÍODO DE OCUPACIÓN } \\
\hline & & PDR I & PDR II & INKA & $\mathrm{H}-\mathrm{I}$ \\
\hline Puerta de Juella/Juez Maidana* & Schuel 1919-1920 & $\mathrm{X}$ & $\mathrm{X}$ & & \\
\hline Pukará de Tilcara * & Schuel 1929 & & $\mathrm{X}$ & $\mathrm{X}$ & $\mathrm{X}$ \\
\hline Muyuna ${ }^{*} \#$ & Schuel 1929 & $\mathrm{X}$ & & & \\
\hline Chijra \# & Schuel 1929 & & $?$ & $\mathrm{X}$ & \\
\hline (Abra/Angosto de) Perchel ${ }^{*} \#$ & Schuel 1929 & & $?$ & $\mathrm{X}$ & \\
\hline Huaco * & Schuel 1929 & $?$ & & & \\
\hline Chucalezna * & Catálogo NMAI & & $\mathrm{X}$ & & \\
\hline
\end{tabular}

* Procedencias registradas en el catálogo del NMAI. \# Procedencias verificadas para materiales del lote Calilegua.

corresponden a lo que Horta (2012) ha definido como "estilo Circumpuneño", caracterizado por el predominio de figuras humanas, a veces con alter ego o máscara en forma de felino y el tema de la decapitación. También hay algunos ejemplares con forma de quirquincho (Dasypus sp.) que, según adelanta la misma autora, se adscribirían a una variante del "estilo Atacameño" (Horta et al. 2016: 106). Todas estas piezas provienen de sitios que se ubican fundamentalmente en los Períodos de Desarrollos Regionales II e Inka, es decir, posteriores a 1250 DC, cronología que se ve corroborada en los casos que cuentan con datos específicos de asociación (p. ej. Salas 1945; Palma 1993) o dataciones radiocarbónicas (Cigliano 1967: 226; Nielsen 2006: 75).

Hasta el momento, no se han publicado para la quebrada tabletas asociadas al componente alfarero IAP o que puedan ser atribuidas con certeza al PDR I. Los elementos del complejo alucinógeno conocidos para esta época son de hueso e incluyen algunas espátulas, cucharitas y estuches encontrados en La Isla (Debenedetti 1910) y San José (Pelissero 1995), además de un fragmento de tubo inhalatorio de madera de este último sitio. Una causa probable de la falta de evidencia es la poca conservación de la madera debido a la costumbre, predominante en este período, de inhumar en forma directa a los difuntos en fosas circulares sin revestimiento. Debenedetti (1910: 231) declara no haber encontrado ningún objeto de este material en La Isla, hecho que atribuye a la falta de buenas maderas en la zona, mientras que Schuel (1929: 1435) advierte el problema en Muyuna, donde los utensilios de madera estaban "en su mayoría podridos". Esto cambia en el PDR II-Inka, cuando se generaliza la costumbre de inhumar en sepulcros revestidos en piedra, a menudo con cubierta del mismo material, lo que da cuenta de la mejor preservación de la madera y la relativa abundancia de tabletas de contextos tardíos.

A estos implementos hay que agregar los tubitos confeccionados con diáfisis de huesos de aves que, de acuerdo al reciente estudio de Berenguer y Acevedo (2015), fueron también instrumentos chamánicos, empleados específicamente como goteros para introducir líquidos alucinógenos o medicinales en cavidades corporales. Un ejemplar de estos artefactos, con su característico tapón, fue recuperado en la tumba 21 de la Necrópolis A (NeA21) de La Isla junto a los esqueletos de tres individuos y un rico acompañamiento que incluía, entre otros objetos, varias piezas cerámicas de estilo Isla Polícromo, dos caracoles terrestres, cuentas de malaquita, mineral de cobre, ocho plaquitas de oro, dos puntas de flecha y un núcleo de obsidiana, fragmentos de yeso y de pintura roja -substancias que Berenguer y Acevedo (2015) observan adheridas en algunos de los goteros analizados en su trabajo- $y$ tres de las espátulas características de los equipos de inhalar. Estas últimas 
Tabla 5. Tabletas de inhalar del lote Calilegua. Table 5. Snuff trays from the Calilegua lot.

\begin{tabular}{|c|c|c|c|c|c|}
\hline \multirow{2}{*}{ GRUPO } & \multicolumn{2}{|c|}{ APÉNDICE } & \multirow{2}{*}{$\begin{array}{l}\text { CAVIDAD } \\
\text { BANDEJA }\end{array}$} & \multirow{2}{*}{$\#$} & \multirow{2}{*}{ OBSERVACIONES } \\
\hline & TRATAMIENTO & ICONOGRAFÍA & & & \\
\hline \multirow{6}{*}{1} & Plano & Sin decoración & Hiperboloide & 133652 & Unión ap-bja continua \\
\hline & Plano & Sin decoración & Hiperboloide & 133653 & Unión ap-bja destacada \\
\hline & Plano & Sin decoración & Rectangular & 133654 & Unión ap-bja destacada \\
\hline & Plano & Sin decoración & Hiperboloide & 133655 & Unión ap-bja destacada \\
\hline & Plano, inciso & Mujer heráldica & Rectangular & 133657 & Unión ap-bja destacada \\
\hline & Plano + volumétrico & Felino echado & Rectangular & 133659 & Unión ap-bja continua \\
\hline \multirow{4}{*}{2} & Volumétrico & Cabeza de camélido & Rectangular & 133648 & "Cola" \\
\hline & Volumétrico & Cabeza de felino? & Rectangular & 133656 & "Cola" \\
\hline & Volumétrico & Cabeza de ofidio & Hiperboloide & 133651 & \\
\hline & Volumétrico & ave & $?$ & 133660 & Fragmentos \\
\hline 3 & Volumétrico & 2 antropomorfos \& ave & Trapezoidal & 133658 & \\
\hline \multirow{2}{*}{$?$} & Volumétrico & ¿? & Hiperboloide & 133649 & Fracturada \\
\hline & Volumétrico & ¿? & Rectangular & 133650 & Fracturada \\
\hline
\end{tabular}

llevan a pensar que la sepultura pudo incluir también tabletas de madera que no se conservaron (Debenedetti 1910: 41, figs. 177 y 178).

\section{La Parafernalia Alucinógena}

En el lote Calilegua hay un mínimo de 37 piezas vinculadas al consumo de alucinógenos: 13 tabletas de madera, fragmentos de 10 tubos de inhalar de madera, 12 espátulas o chucharitas (cinco de madera, siete de hueso) y, por lo menos, dos tubitos-goteros de hueso.

Dos de las tabletas están incompletas, por lo que no es posible clasificarlas adecuadamente. Las restantes corresponden a tres grupos estilísticos diferentes (tabla 5). El primero incluye los ejemplares con apéndice plano de contorno rectangular o ligeramente trapezoidal con el borde superior curvo (fig. 7). De los dos ejemplares decorados, uno lleva incisa la Mujer Heráldica (fig. 1) y el otro muestra un felino echado que ha sido tallado en forma volumétrica (fig. 7a). Las motas del animal se representaron mediante la incrustación de cuentas de color verde y blanco.

El segundo grupo, caracterizado por un apéndice zoomorfo trabajado volumétricamente, puede encuadrarse en lo que Horta et al. (2016) definen como "estilo Atacameño" (fig. 8). Aunque estas piezas están muy deterioradas, es posible distinguir que representan animales diferentes. Uno de ellos parece ser un camélido (fig. 9a), a juzgar por sus semejanzas con el modo en que se muestran estos animales en ciertos tubos de inhalar, con grandes orejas aguzadas y recogidas hacia atrás (cf. Llagostera et al. 1988; Tarragó 1989: 409-410). Según Torres (1987, Pl. 145) el segundo sería un ofidio, mientras que Horta et al. (2016: tabla 1) lo interpretan como felino. Observando el apéndice en detalle, sin embargo, resulta claro que, si bien el rostro ha sido plasmado con 

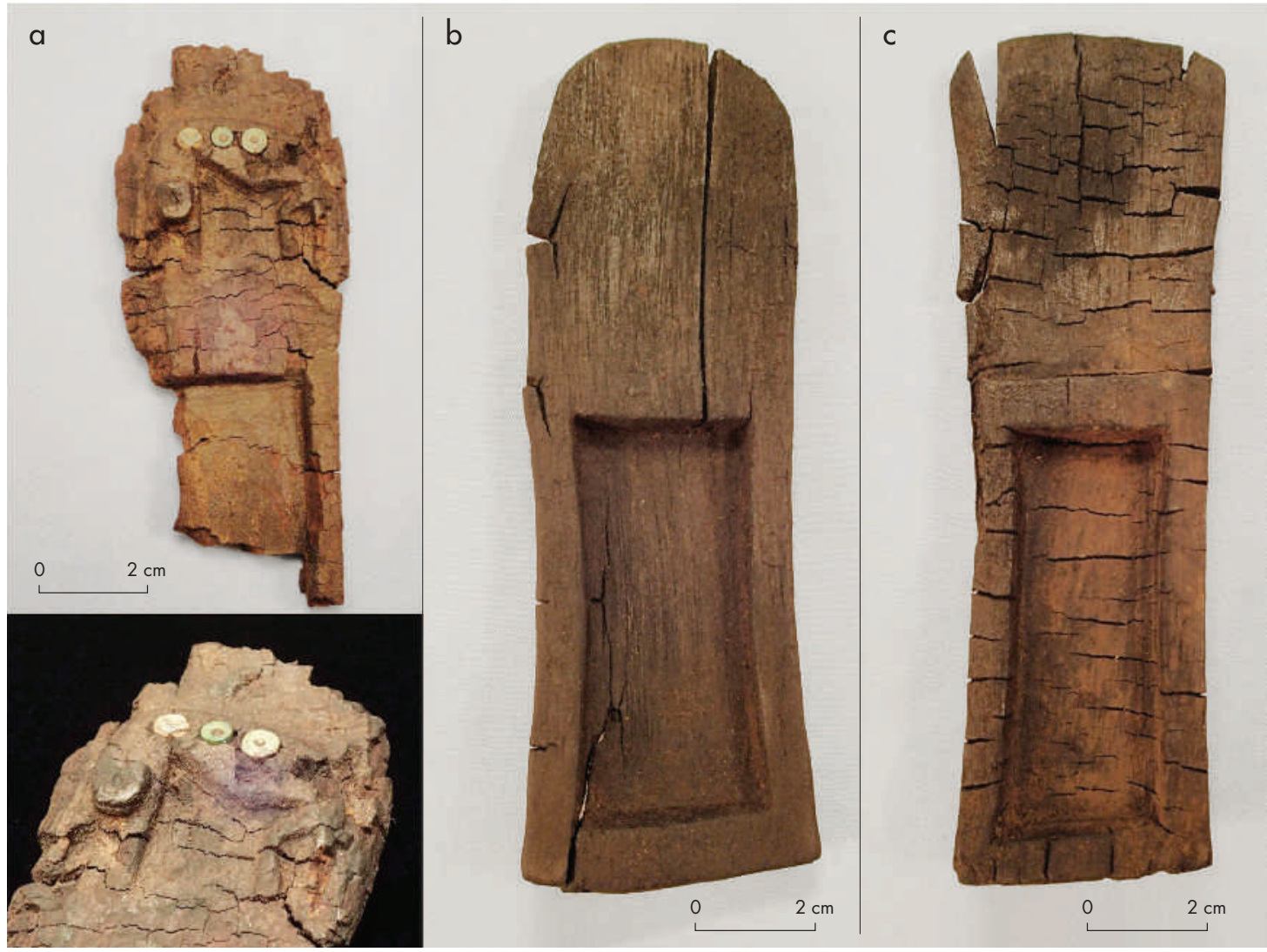

Figura 7. Tabletas con apéndice plano: a) con felino tallado ( $\left.\mathrm{n}^{\circ} 133659\right)$; b-c) sin decoración $\left(\mathrm{n}^{\circ} 133652, \mathrm{n}^{\circ} 133654\right)$. Figure 7 . Flatappendix snuffing trays: a) with carved feline ( $\left.\left.n^{\circ} 133659\right) ; b-c\right)$ undecorated ( $\left.n^{\circ} 133652, n^{\circ} 133654\right)$.
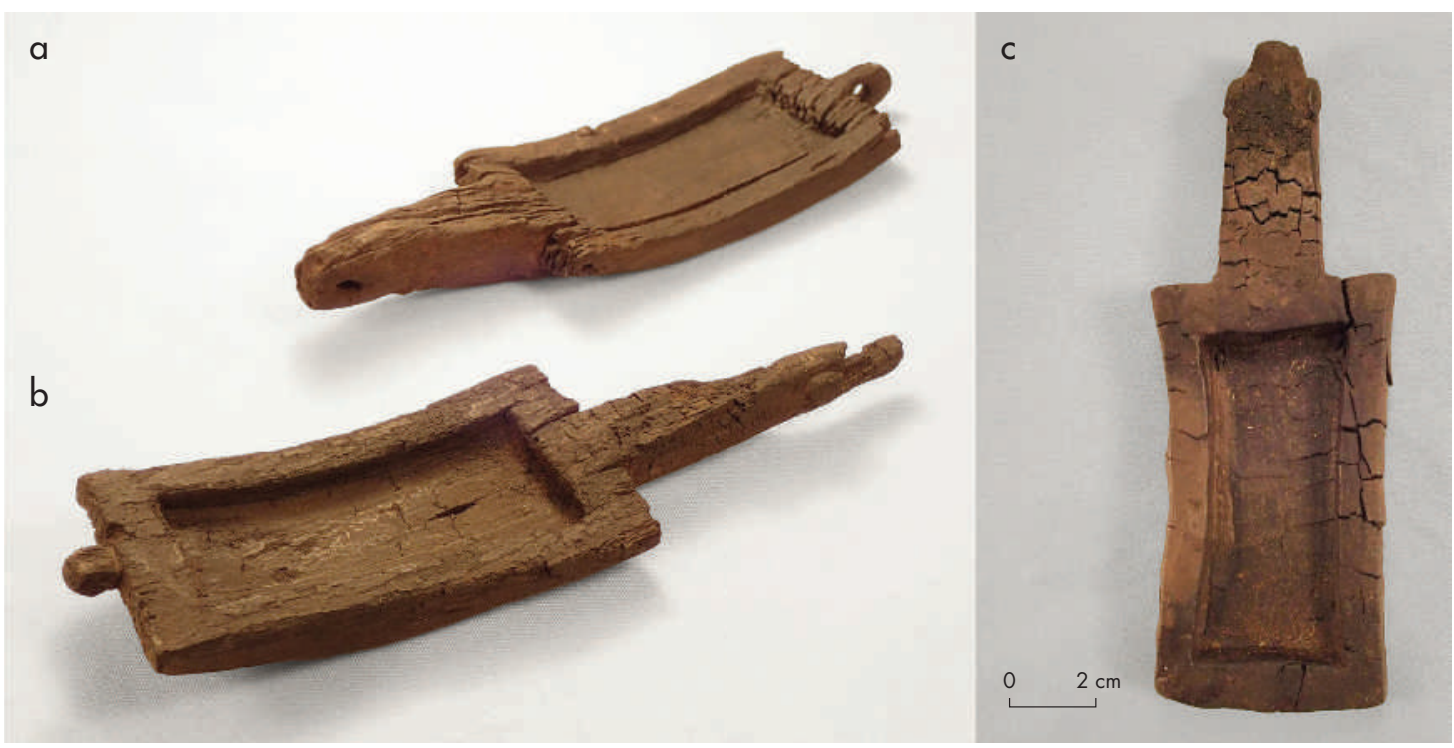

Figura 8. Tabletas con un apéndice zoomorfo: a) $n^{\circ} 133648$; b) $n^{\circ} 133656$; c) $n^{\circ} 133651$. Figure 8. Snuffing trays with zoomorphic appendices a) $\left.n^{\circ} 133648 ; \boldsymbol{b}\right) n^{\circ} 133656$; c) $n^{\circ} 133651$. 

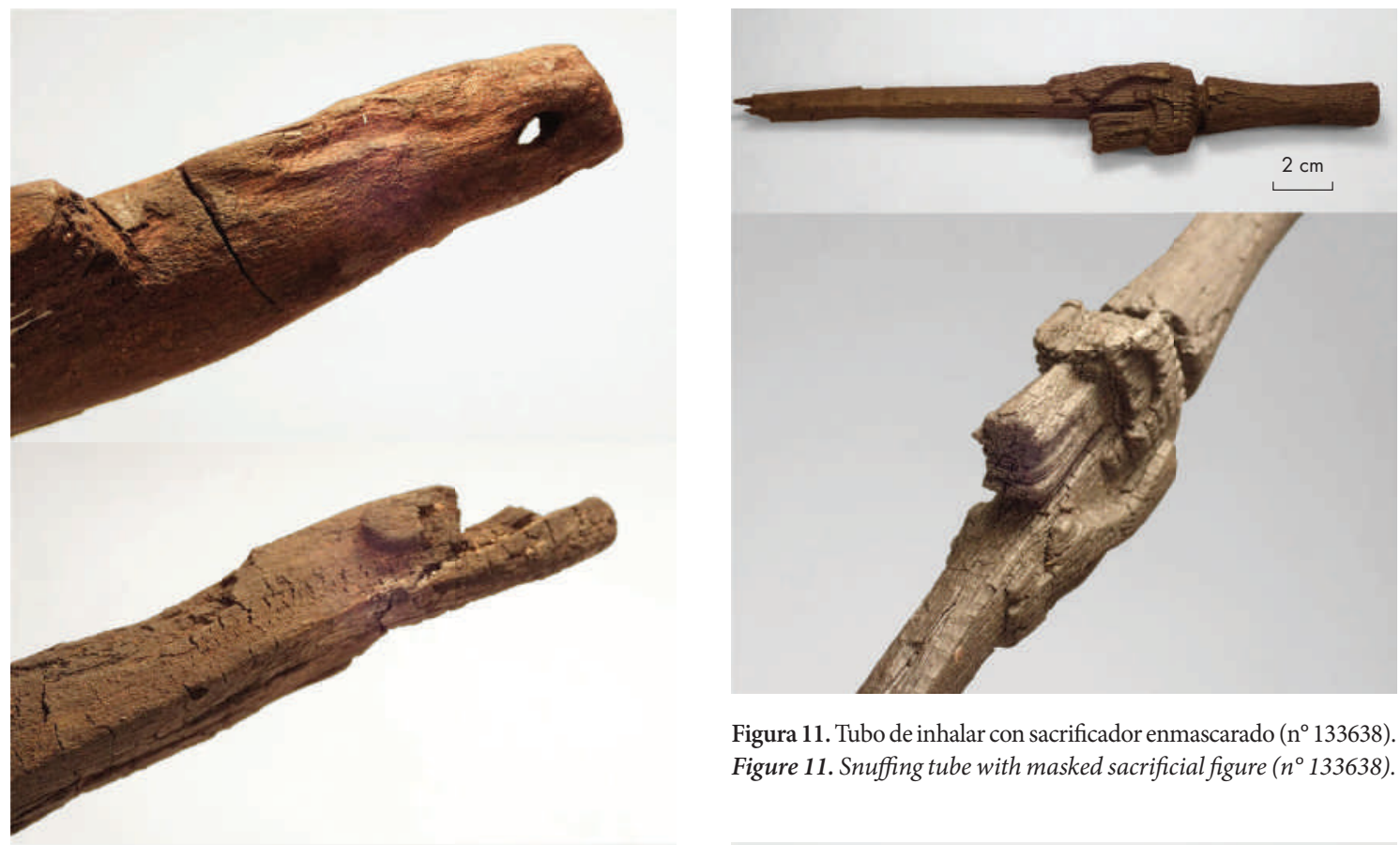

Figura 11. Tubo de inhalar con sacrificador enmascarado $\left(\mathrm{n}^{\circ} 133638\right)$. Figure 11. Snuffing tube with masked sacrificial figure ( $\left.n^{\circ} 133638\right)$.
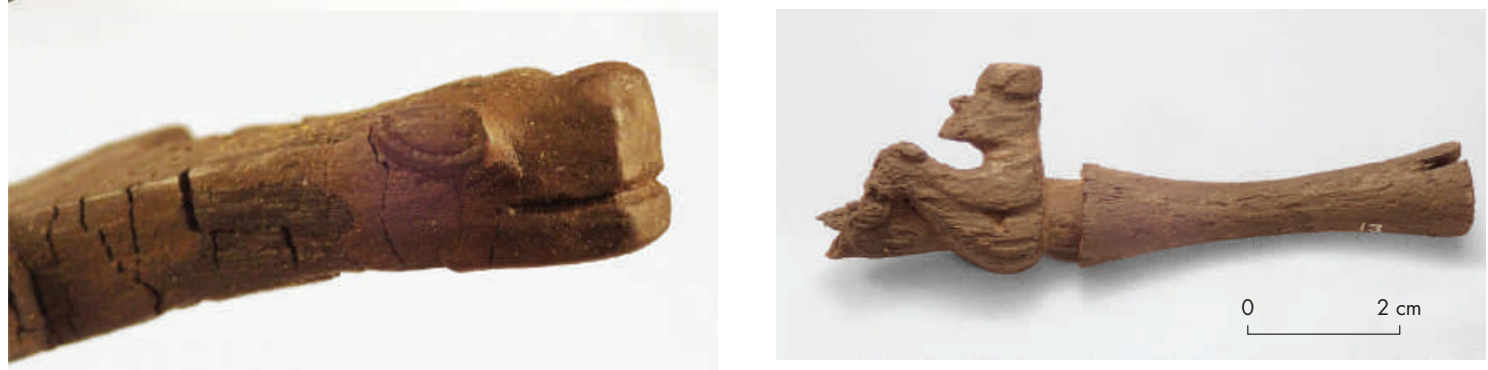

Figura 9. Detalle de los apéndices. Figure 9. Detail of the appendices.

Figura 12. Tubo de inhalar con personaje con piernas recogidas $\left(\mathrm{n}^{\circ}\right.$ 133637). Figure 12. Snuffing tube with squatting figure ( $\left.n^{\circ} 133637\right)$.
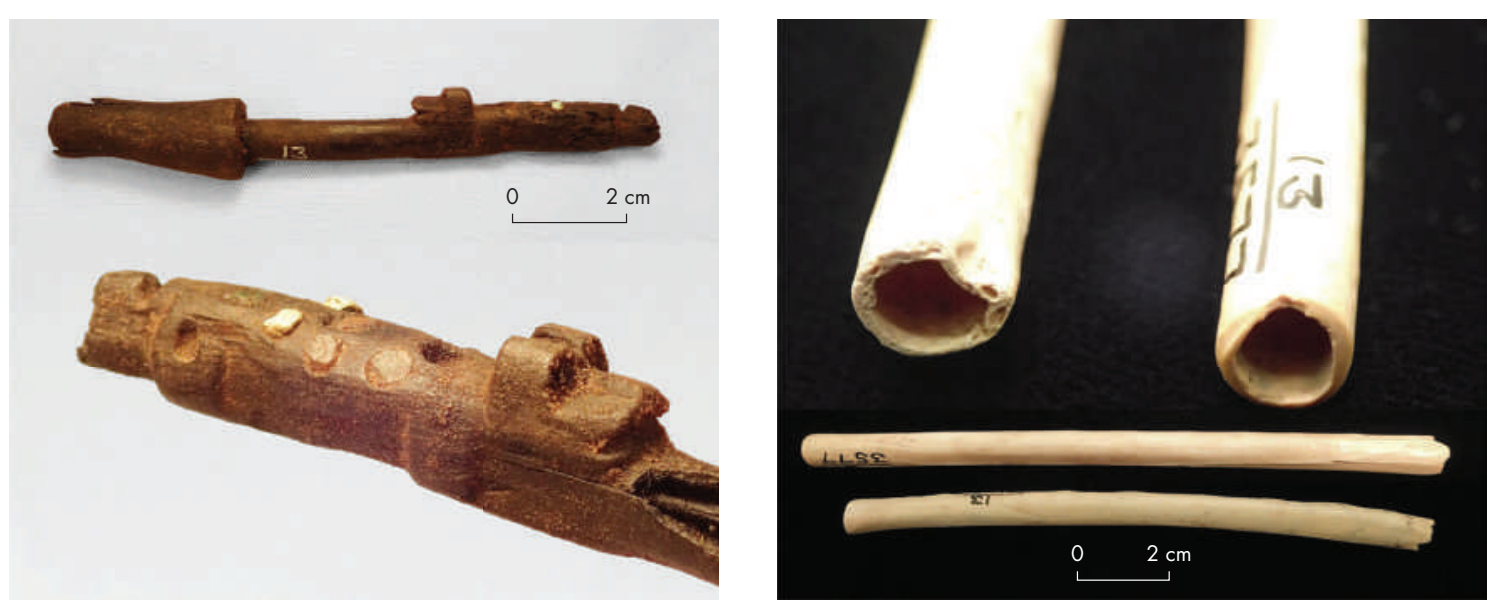

Figura 10. Tubo con felino montado $\left(\mathrm{n}^{\circ} 133636\right)$. Figure 10. Tube with attached feline ( $\left.n^{\circ} 133636\right)$.

Figura 13. Tubos goteros en el lote Calilegua ( $\left.{ }^{\circ} 133577\right)$. Figure 13. Droppers in the Calilegua lot ( $\left.n^{\circ} 133577\right)$. 
cierto naturalismo, no se han indicado los colmillos ni los ojos redondos que denotan al felino en los demás ejemplares del tipo (fig. 9b). El tercero, en cambio, está muy deteriorado, pero conserva el ojo circular característico de este animal (fig. 9c). Del cuarto ejemplar solo puede decirse que se trata de un ave $\left(n^{\circ} 133660\right)$.

La única tableta que integra el tercer grupo se encuentra muy bien conservada (fig. 5c), lo que sugiere que proviene de un sitio diferente a las demás. Los apéndices muestran dos antropomorfos tomándose las rodillas y, entre ellos, lo que parecería ser un cóndor, teniendo en cuenta el énfasis puesto en representar su collar. Este ejemplar se adscribe al estilo Circumpuneño (Horta 2012).

De los tubos, siete conservan solamente la pieza de forma hiperboloide que comúnmente sirve para asirlos. Los otros cuatro también están fragmentados, pero se reconoce en ellos parte de la iconografía, que se ajusta a los tres tipos que Sprovieri (2010: 97) registra en el valle Calchaquí y que tienen paralelismos en otras regiones del NOA y del norte de Chile. Uno de ellos lleva montado sobre el tubo un felino cuyas motas se han indicado como pequeñas incrustaciones de rocas verdes y blancas (fig. 10), un detalle que lo vincula a la tableta de la figura 9. Los restantes podrían adscribirse al estilo Circumpuneño. Uno muestra al sacrificador con todos sus atributos, máscara felínica, hacha y cabeza cercenada (fig. 11), otro lleva un motivo similar pero está muy deteriorado, y el tercero representa un antropomorfo con las piernas recogidas (fig. 12). Ejemplares comparables han sido registrados en sitios del PDR IIInka de la quebrada, como Ciénaga Grande (Salas 1945: 207-208) y Angosto Chico (Casanova 1942: lám. ViII). En tanto, un tubo similar al ilustrado en la fig. 12, con un personaje "sentado en cuclillas" (Ambrosetti 1904: 22) que sostiene un hacha en una mano y lo que parece una trompeta en la otra, fue encontrado en asociación con cerámica Inka en un sepulcro de Antofagasta de la Sierra (puna meridional), lo que establece un claro jalón cronológico tardío para este estilo.

En cuanto a los goteros, se reconocen dos ejemplares que han sido agrupados ( $\left.\mathrm{n}^{\circ} 133577\right)$ con otros 17 tubos de hueso de diferente largo, grosor y terminación que evidentemente prestaron funciones diversas. Sus medidas y características de manufactura coinciden con las detalladas por Berenguer y Acevedo (2015) para este tipo de implementos, pero no se han conservado el tapón, el material leñoso interior ni la tripa (fig. 13).

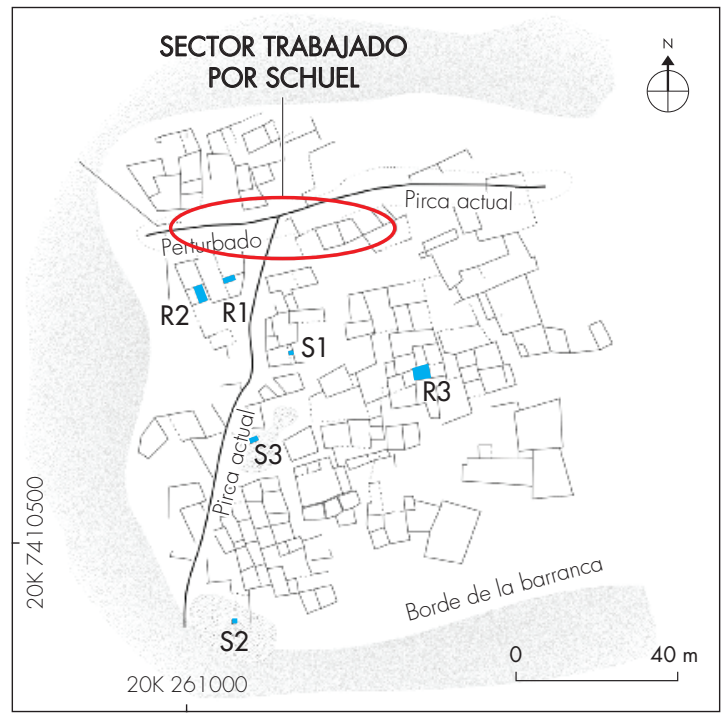

Figura 14. Planimetría de Muyuna indicando el área trabajada por Schuel y la ubicación de las excavaciones recientes. Figure 14. Map of Muyuna, indicating the area investigated by Schuel and the location of recent excavations.

Uno de ellos, sin embargo, tiene marcas en el extremo opuesto al borde biselado, que podrían corresponder a la fijación de esta última parte al tubo.

\section{PARAFERNALIA ALUCINÓGENA EN CONTEXTO: MUYUNA REVISITADO}

Muyuna es un sitio conglomerado emplazado sobre una terraza fluvial alta en la margen izquierda del río Grande de Humahuaca, cerca de la localidad de Chucalezna, a $2.850 \mathrm{msnm}$. Al pie del mismo, la llanura aluvial es bastante amplia, ofreciendo excelentes posibilidades para el cultivo con riego. Durante los años 1994 y 2000 se realizaron investigaciones en este sitio con el objetivo de generar nuevos datos sobre la cronología y los contextos asociados a los estilos Isla y Alfarcito Polícromo, predominantes entre los materiales cerámicos visibles en superficie, y aportar así elementos para entender mejor la sociedad de la época. Los trabajos comprendieron el relevamiento planimétrico de la arquitectura, muestreos de artefactos en superficie y la excavación de cuatro pozos de sondeo, partes de dos patios (Recintos 1 y 2 ) y una habitación completa (Recinto 3 ). En el contexto de esta discusión, interesan los datos obtenidos sobre la cronología general del sitio y en particular los hallazgos 
Tabla 6. Dataciones radiocarbónicas de Muyuna. Table 6. Radiocarbon dating of Muyuna.

\begin{tabular}{c|c|c|c|c} 
CONTEXTO & CÓDIGO & AÑOS AP & $\mathrm{dC/cal} \mathrm{p=95,4 \%}$ & ASOCIACIÓN / EVENTO DATADO \\
\hline S3, Basural 2,80 m & LP-1467 & $1230 \pm 50$ & $690-990$ & Cer. N/R, ¿estilo Alfarcito bicolor? \\
\hline S1, basural 0,80 m & AA-13668 & $1022 \pm 50$ & $980-1180$ & Cer. tricolor motivo puntos blancos \\
\hline Recinto 3, rasgo 8 & Beta-149929 & $900 \pm 40$ & $1040-1280$ & Cer. tricolor \\
\hline Recinto 3, techo & LP-1460 & $880 \pm 60$ & $1040-1290$ & Cer. tricolor, abandono del recinto \\
\hline Recinto 2, piso I & LP-1301 & $850 \pm 80$ & $1040-1380$ & $\begin{array}{c}\text { Cer. tricolor motivo puntos blancos } \\
\text { \& estilo Alfarcito Polícromo. }\end{array}$
\end{tabular}

Calibraciones realizadas con Ox Cal 3.10, utilizando datos para el hemisferio sur de McCormack et al. (2004).

del Recinto 3, ya que incluyen elementos del complejo alucinógeno similares a los presentes en el lote Calilegua. En la figura 14 se indica la ubicación de estas excavaciones, así como el principal sector intervenido por Schuel, de donde seguramente fueron extraídos gran parte de los materiales de la colección.

Las recolecciones mostraron un claro predominio del componente IAP en la cerámica decorada de superficie, lo que ubica al sitio fundamentalmente en el PDR I, estimación que se ve confirmada por las dataciones realizadas hasta ahora. También se encontraron dos o tres fragmentos Alfarcito Bicolor cerca del límite sur del sitio que delataban una ocupación anterior (componente AA). Esta pudo ser identificada en el sondeo 3 ( $2 \times 1$ $\mathrm{m})$, realizado en un basural ubicado hacia el centro del sitio, cuya capa más profunda $(0,65-0,80 \mathrm{~m})$ contenía cerámica bicolor exclusivamente y arrojó una fecha de fines del primer milenio (tabla 6). Este componente no se encontró en el siguiente basurero sondeado hacia el norte (sondeo 1), de cuya base proviene la segunda datación (1022 \pm 50 AP), asociado a cerámica Isla Polícromo y Peñas Coloradas con puntos blancos (componente IAP). Tampoco se obtuvieron fechas o materiales tempranos en los demás sectores excavados, lo que sugiere que la ocupación del primer milenio debe encontrarse hacia el centro-sur del sitio, por lo que no fue alcanzada durante las excavaciones de Schuel (fig. 14).

El Recinto 3 es una habitación construida con muros dobles de piedra asentada con mortero de barro, originalmente techada y con un vano en el ángulo suroeste que la comunica a un recinto de mayor tamaño, posiblemente un patio. Se excavó en su totalidad hasta nivel estéril, identificando tres contextos estratigráficos que dan testimonio de otros tantos momentos en la trayectoria de la estructura. El primero, correspondiente a su construcción y uso, comprende la huella de un poste calzado con piedras (rasgo 1), un fogón en cubeta (rasgo 8, fechado en $900 \pm 40 \mathrm{AP}$ ), la superficie de ocupación con algunos desechos asociados y seis inhumaciones directas que incluían un total de 17 individuos (Seldes 2006) acompañados por diversos objetos (tabla 7; fig. 15). Hacia el final de la ocupación se depositó junto al poste, o a su huella si había sido ya retirado, un conjunto de trozos de mineral cuprífero y 16 cuentas enteras, fragmentadas y preformas de ceniza volcánica (fig. 16). Cuentas similares son frecuentes en los contextos funerarios de comienzos del segundo milenio, desde La Isla (Debenedetti 1910: 241-243) hasta San Pedro de Atacama (Tarragó 1989: 451). Los desechos del piso, acumulados hacia el norte de la estructura, incluían fragmentos cerámicos, líticos, óseos, un retocador de hueso, una mano de moler y dos cuellos de cántaros (rasgos 2 y 3), uno de ellos con diseños pintados de estilo Alfarcito Polícromo.

El segundo contexto estratigráfico comprende una capa compacta color verdoso de hasta $5 \mathrm{~cm}$ de espesor, que se aplicó en toda la estructura como un sello sobre el piso de ocupación y, sobre ella, restos de madera y paja incinerados y terrones de barro consolidado (torta) correspondientes al techo quemado. Mezclados en este nivel por todo el recinto había granos de maíz carbonizados y fragmentos de un gran cántaro alisado. Esta unidad representa un gesto de abandono deliberado del recinto, un rito de clausura de la vivienda que tal vez incluyó la 
Tabla 7. Contextos funerarios del Recinto 3. Table 7. Funerary settings in Recinto 3.

\begin{tabular}{|c|c|c|c|c|}
\hline ORDEN* & $\mathbf{N}^{\circ}$ & $\mathrm{N}^{\circ}$ INDIVIDUO, EDAD & SEXO & ACOMPAÑAMIENTO \\
\hline \multirow[t]{2}{*}{ I } & 7 & $\begin{array}{l}1, \text { neonato } 15 \text { días } \pm 15 \text { días } \\
2 \text {, neonato } 15 \text { días } \pm 15 \text { días } \\
3 \text {, adulto }\end{array}$ & $\begin{array}{c}i ? \\
i ? \\
\text { Femenino }\end{array}$ & $\begin{array}{l}\text { - pigmento ocre } \\
\text { - mineral } \mathrm{Cu}\end{array}$ \\
\hline & 10 & $\begin{array}{l}4 \text {, adulto joven } 20-25 \text { años } \\
5 \text {, adulto } 24-30 \text { años }\end{array}$ & $\begin{array}{c}\text { Femenino } \\
i ?\end{array}$ & $\begin{array}{l}\text { - Cordeles y frgs. de calabaza (c/ind. 4)** } \\
\text { - Tableta y tubo de inhalar de madera (c/ind. 5) } \\
-1 \text { vaso c/cintura Isla bicolor fragmentado } \\
1 \text { escudilla Int. Negro Pulido fragmentado } \\
\text { Restos de tejido } \\
\text { Restos de cestería } \\
2 \text { falanges de camélido (llama) } \\
\text { Marlos de maíz } \\
\text { Artefactos de madera no identificables }\end{array}$ \\
\hline \multirow[t]{2}{*}{ II } & 9 & $\begin{array}{l}6 \text {, infantil } 1 \text { año } \pm 1 \text { año } \\
7 \text {, adulto joven } \\
8 \text {, adulto } \\
9 \text {, adulto }\end{array}$ & $\begin{array}{c}i ? \\
\text { Femenino } \\
\text { Masculino } \\
\text { Femenino }\end{array}$ & $\begin{array}{l}5 \text { cuentas verdes (mineral Cu?) } \\
4 \text { tubos de hueso de ave (c/ind. 8) }\end{array}$ \\
\hline & 5 & $\begin{array}{l}10 \text {, neonato } 1 \text { mes } \pm 1 \text { mes } \\
11 \text {, neonato } \\
12 \text {, infantil } 3 \text { años } \pm 6 \text { meses } \\
13 \text {, adulto joven } \\
14 \text {, adulto } \\
15 \text {, adulto }\end{array}$ & $\begin{array}{c}\dot{2} ? \\
\dot{i} ? \\
i ? \\
\text { Masculino } \\
\text { Masculino } \\
\text { Femenino }\end{array}$ & $\begin{array}{l}4 \text { puntas de flecha pedunculadas } \\
\text { Fragmentos de astiles } \\
1 \text { frg. tableta de inhalar } \\
1 \text { frg. estuche de madera } \\
1 \text { aguja de espina de cardón } \\
1 \text { frg. vaso c/cintura pulido } \\
1 \text { ollita Isla bicolor } \\
1 \text { yuro alisado } \\
1 \text { jarro c/hollín } \\
1 \text { escudilla miniatura N/R (desfoliada) } \\
1 \text { vaso c/cintura miniatura alisado } \\
\text { Mineral Cu }\end{array}$ \\
\hline \multirow[t]{2}{*}{ III } & 6 & 16 , neonato 15 días \pm 15 días & ¿? & \\
\hline & 4 & 17 , neonato 15 días \pm 15 días & ¿? & \\
\hline
\end{tabular}

* Orden en que fueron realizadas las inhumaciones. ${ }^{* *}$ Sólo se especifica cuando pudieron establecerse asociaciones con individuos particulares dentro de la sepultura.

ofrenda de cuentas y los cuellos de cántaros, ya que se encontraron insertos en el sello de arcilla verdosa. La datación de $880 \pm 60 \mathrm{AP}$, realizada sobre la paja de techo, ubicaría cronológicamente este evento y el final de la ocupación de la vivienda. Por encima de este nivel se acumuló la tercera unidad estratigráfica, un relleno de 0,20 a $0,40 \mathrm{~m}$ de espesor formado por el derrumbe de los muros y arena fina de origen eólico. La ausencia de otros desechos culturales en este contexto indica que todo el sector, tal vez el sitio entero, se encontraba abandonado durante su acumulación.
Como muestra la tabla 7, tres de las cuatro sepulturas que incluyen adultos contienen objetos del complejo alucinógeno, aunque solo se recuperaron fragmentos muy deteriorados debido a la ausencia de revestimientos en las fosas. En la número 10, se trata de una tableta con un apéndice y fragmentos de un tubo conteniendo espinas de cardón (fig. 17a), ambos directamente asociados al cuerpo de un adulto de sexo indeterminado. El apéndice de esta tableta es semejante a la ${ }^{\circ} 133656$ del lote Calilegua (figs. 8b y 9), mientras que el animal montado sobre el tubo 


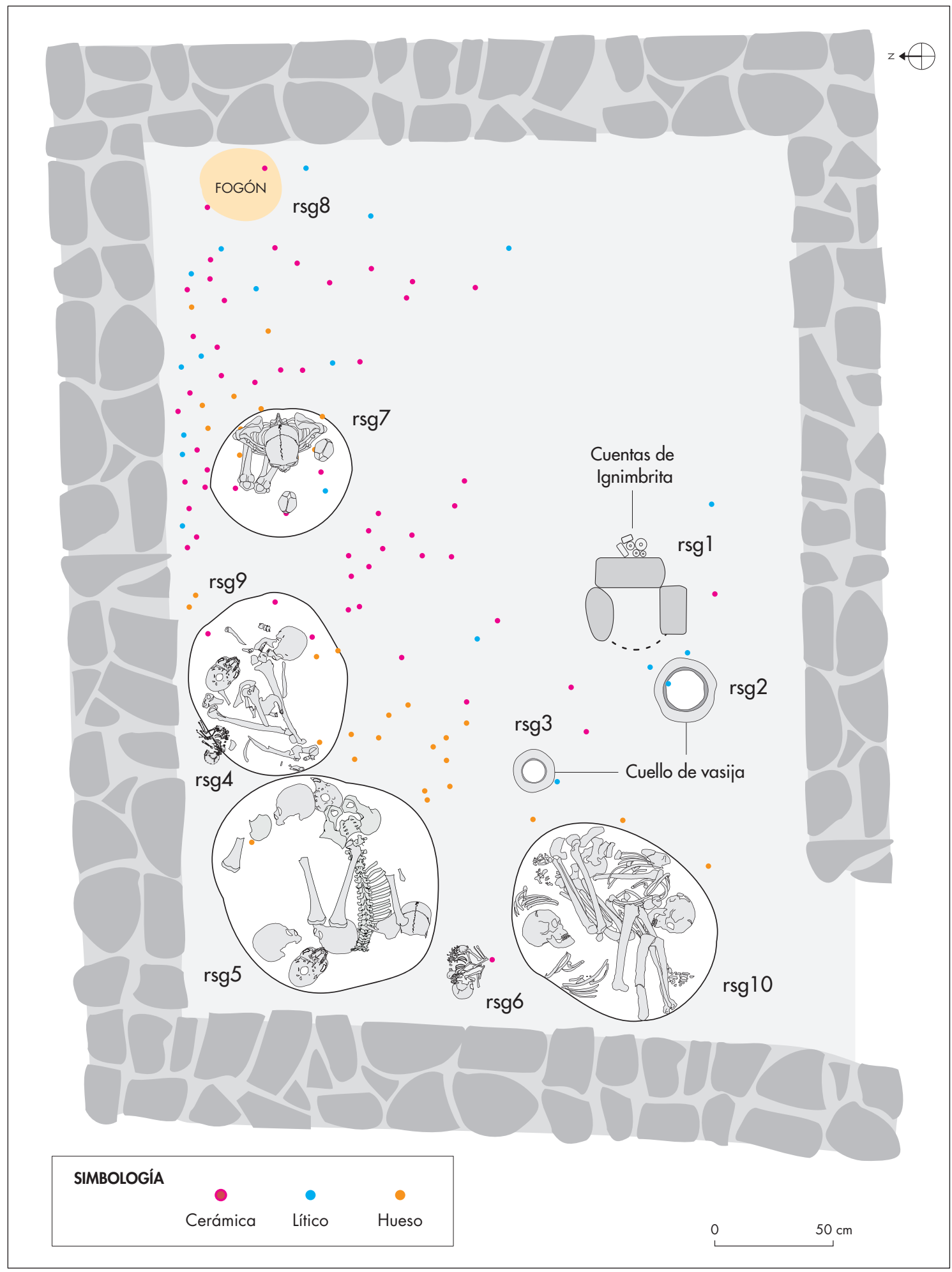

Figura 15. Planta del Recinto 3 indicando la distribución de rasgos y desechos en el piso de ocupación. Figure 15. Diagram of Recinto 3 , indicating the distribution of features and debris in the occupation floor. 


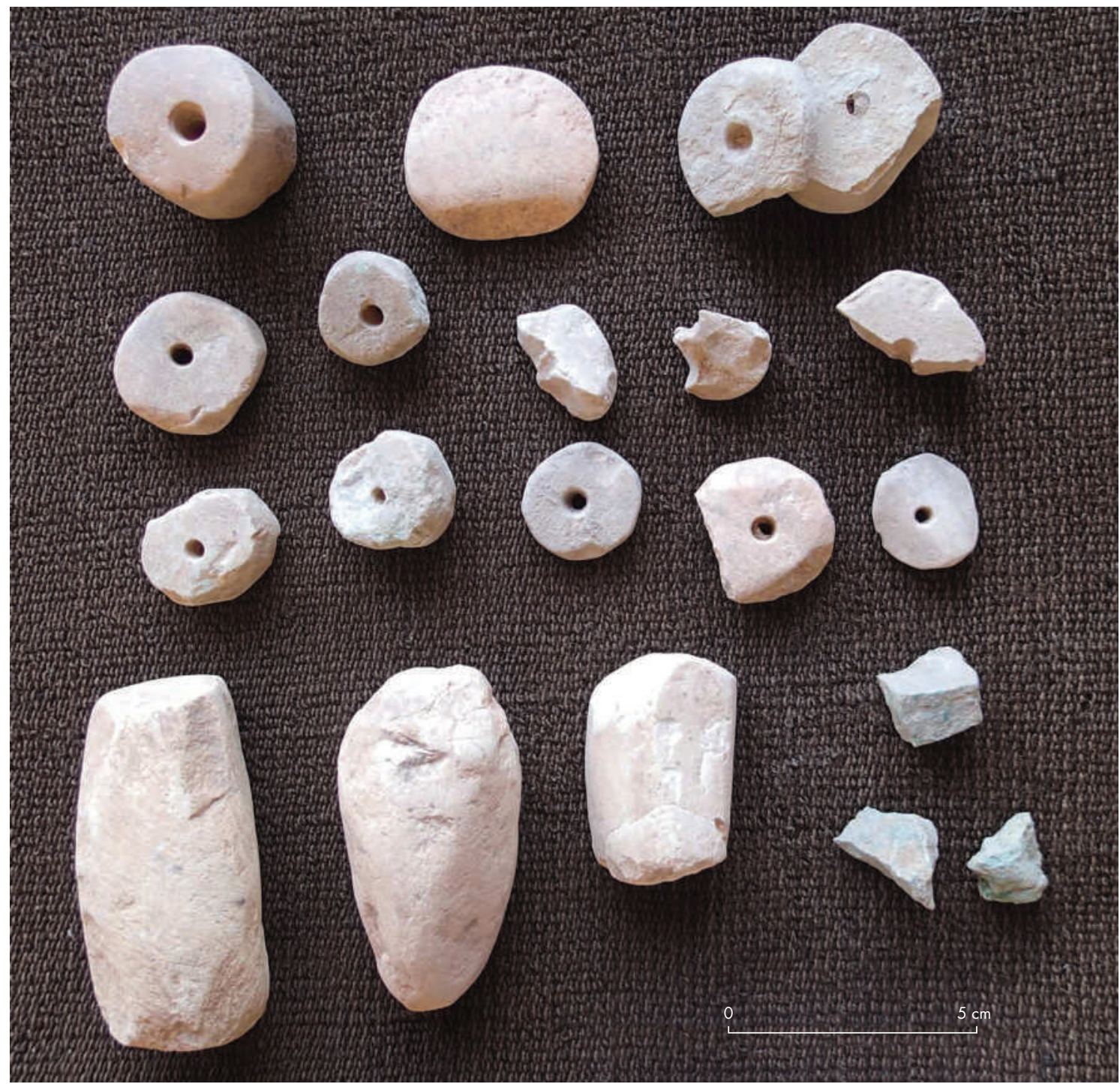

Figura 16. Ofrenda depositada junto al poste central del Recinto 3. Figure 16. Offering deposited next to the main pole of Recinto 3.

recuerda al felino del ejemplar $n^{\circ} 133636$ (fig. 10). En la número 5 se encontraron fragmentos de un estuche cilíndrico de madera y el apéndice de una tableta (fig. 17b) donde se advierte un relieve de forma circular, probablemente el ojo de un felino representado de manera esquemática (Horta et al. 2016). La alteración de la posición original de los huesos de los adultos, inhumados en primer término, por la adición posterior de los neonatos y el infante no permitieron precisar a cuál de los adultos se encontraban asociados estos objetos. En la número 9 se hallaron cuatro tubitos goteros asociados al esqueleto de un hombre adulto.
Dos de los goteros conservan todavía sus tapones perforados en el extremo (fig. 18).

Entre los demás objetos presentes en el registro funerario del Recinto 3, cabe destacar cuentas de mineral de cobre y fragmentos sin trabajar del mismo material, varias piezas cerámicas, todas ellas pertenecientes al componentes alfarero IAP (Interior Negro Pulido, Isla Bicolor, vasos con cintura pulidos), dos falanges de camélido (llama, a juzgar por el tamaño), restos de un contenedor de calabaza, cordeles de fibra vegetal, puntas con sus astiles y otros objetos de madera que no pudieron ser identificados. 


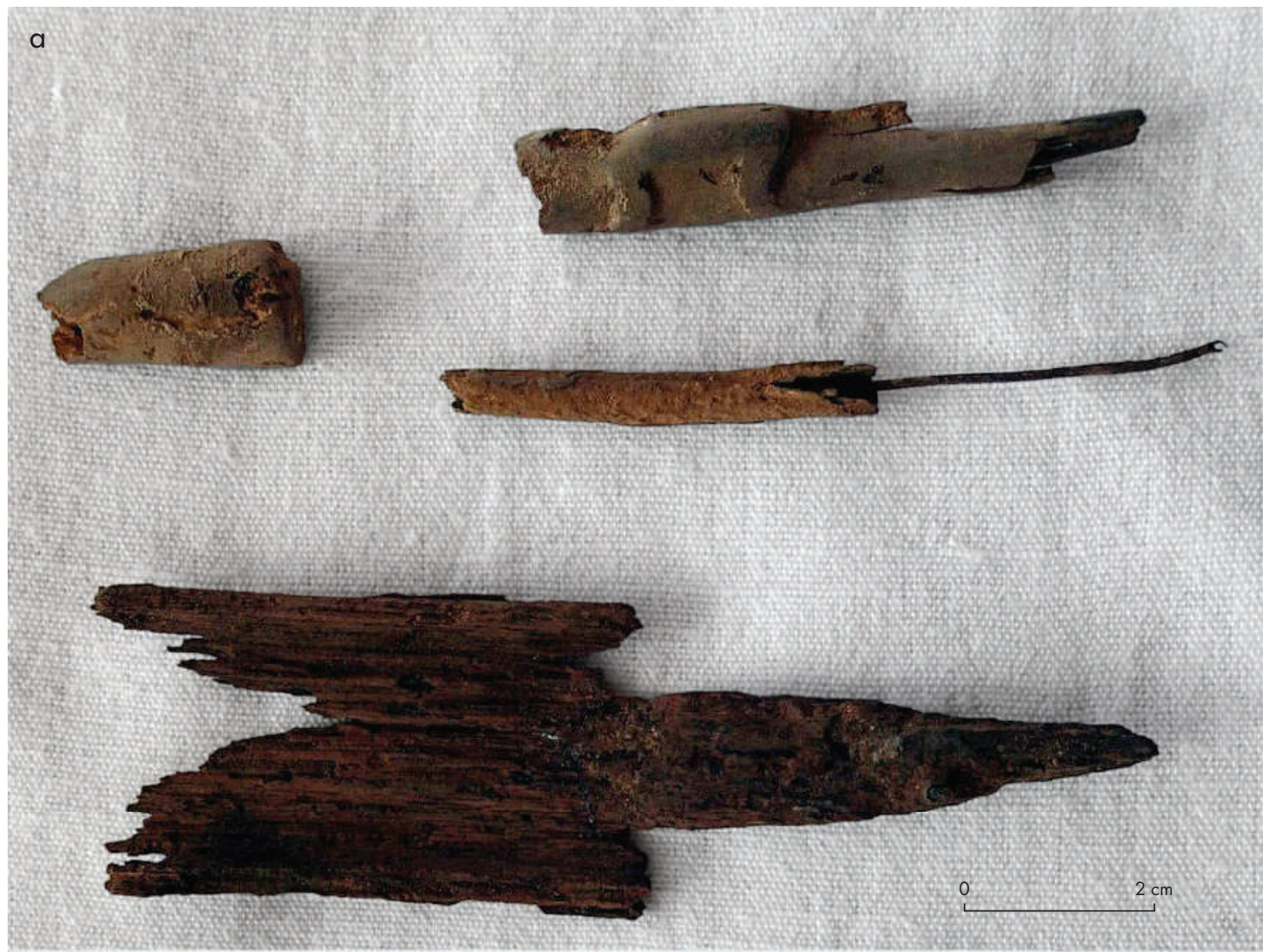

b

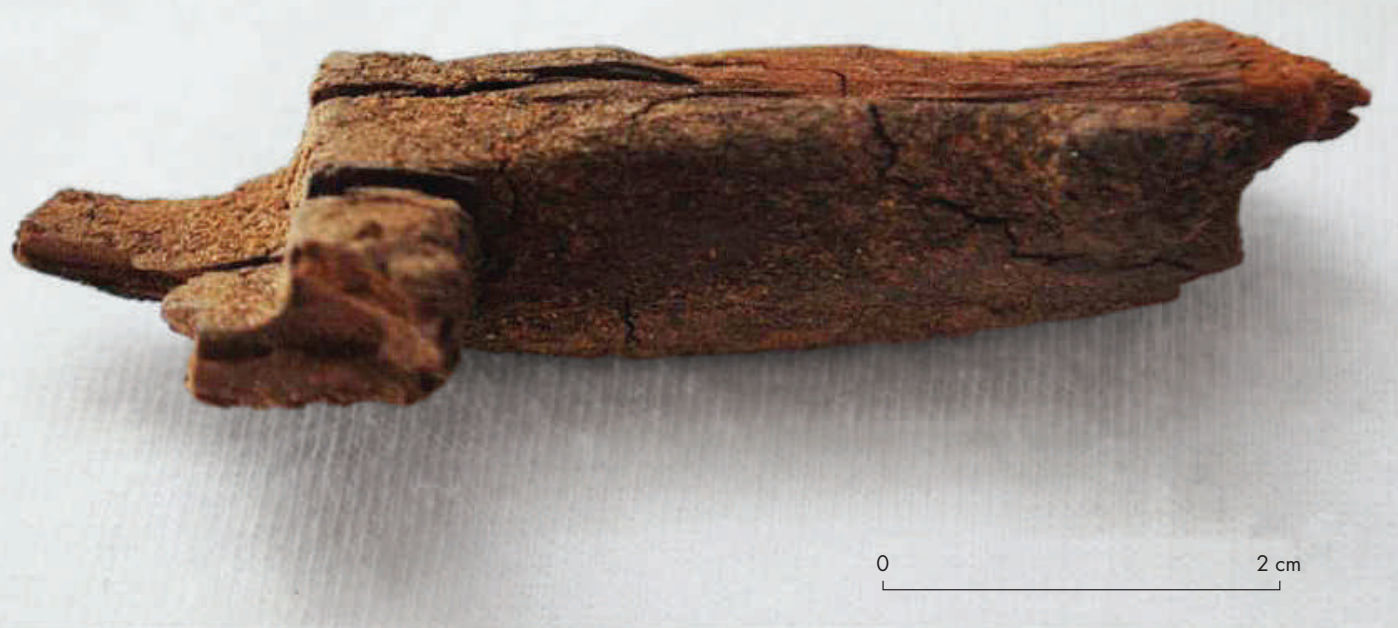

Figura 17. Fragmentos de equipos de inhalar encontrados en los rasgos 10 (a) y 5 (b). Figure 17. Fragments of inhaling instruments found in features $10(a)$ and $5(b)$. 


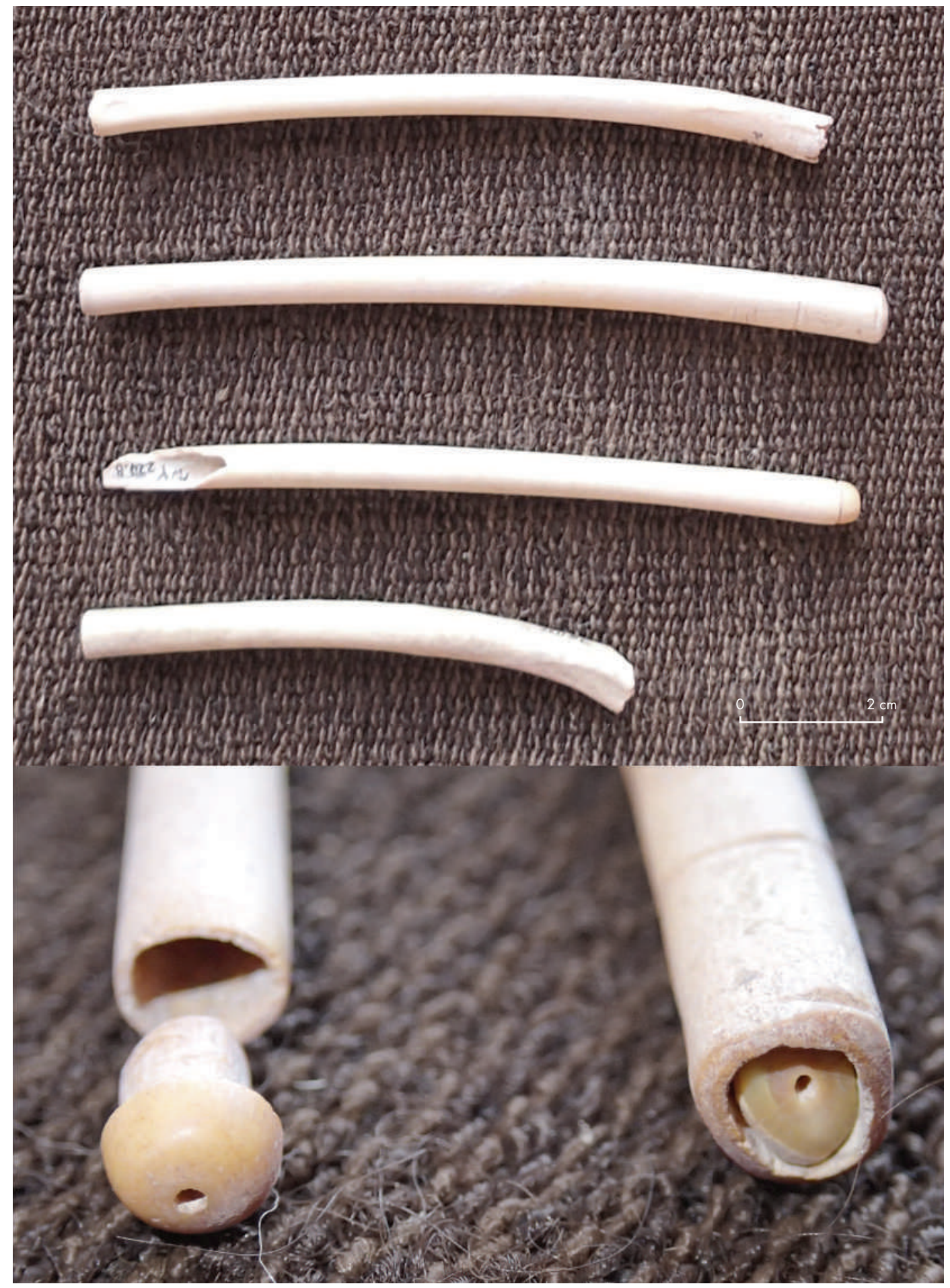

Figura 18. Goteros encontrados en el rasgo 9. Figure 18. Droppers found in feature 9. 
La importancia del maíz para esta comunidad se evidencia en los restos depositados en las sepulturas y durante el rito de abandono, como así también en la elevada frecuencia de polen de esta especie en las distintas muestras analizadas, testimonio de su cultivo en las inmediaciones del sitio. El análisis faunístico reveló un predominio absoluto de los camélidos (97\% de 1130 restos identificados), incluyendo tanto animales grandes (llama) como pequeños (vicuña [Mercolli et al. 2014]). Los perfiles etarios de la muestra indican una explotación mixta de los rebaños, en la que se balancearon el aprovechamiento de la carne con la producción de fibra y el transporte. Otros taxones presentes incluyen aves $(\mathrm{N}=3)$, quirquincho (21 placas) y felino $(\mathrm{N}=1)$. Evidencias adicionales de la importancia de los rebaños son la ofrenda de falanges de llama en el rasgo 10 y el gran corral ubicado hacia el sureste del sitio. Dos fragmentos de moldes hallados en superficie dan testimonio de labores metalúrgicas en el lugar. La única pieza de oro encontrada es una pequeña lámina con dos perforaciones y procede de un nivel intermedio del depósito de desechos ubicado al centro del sitio (sondeo 3 ).

\section{DISCUSIÓN: PARAFERNALIA ALUCINÓGENA EN MOVIMIENTO}

Los elementos hasta aquí presentados permiten estimar los probables sitios de procedencia y cronología de la parafernalia alucinógena del lote Calilegua y, a partir de ello, formular algunas propuestas sobre el significado de estas piezas en el contexto regional. Tomando en cuenta su excepcional conservación, es probable que la tableta con dos antropomorfos y un ave (fig. 5 c) provenga de alguno de los sitios tardíos excavados por Schuel, como Chijra, el pukará de Tilcara o Perchel. No es posible ampliar esta conclusión a los tubos con iconografía "Circumpuneña" (sensu Horta 2012) ya que, aun cuando los materiales de ese estilo encontrados hasta ahora en la región parecen ser tardíos (PDR II-Inka), la escasa información disponible sobre la parafernalia alucinógena del PDR I no permite descartar una mayor antigüedad para el mismo en la quebrada. De hecho, la datación obtenida por Albarracín-Jordán et al. (2014) para dos tabletas con apéndices antropomorfos en Cueva del Chileno (norte de Lípez) demuestran que, en algunos lugares al menos, dicho estilo ya se usaba a comienzos del segundo milenio (cf. Richardin et al. 2015).
Hay buenas razones para pensar que las tabletas de los otros dos grupos estilísticos y el tubo con felino montado datan del PDR I y que su procedencia es Muyuna. El hallazgo de fragmentos de dos tabletas zoomorfas y un tubo con iconografía semejante en el Recinto 3 de ese sitio revela que lo que podría denominarse grupo "zoomorfo con un apéndice" estaba en vigencia en la quebrada por aquella época. Estos ejemplares, junto a los del lote Calilegua, muestran tanto felinos como camélidos, aves y serpientes representados bajo este patrón estilístico, como fuera ya notado por Tarragó (1989: 451) para la fase Yaye de San Pedro de Atacama. La continuidad de las tabletas zoomorfas de un apéndice en el PDR II de la quebrada está indicada por la presencia de ejemplares con forma de quirquincho en sitios como Angosto Chico (p. ej. Casanova 1942) y, en la puna, por una fecha del siglo xIV asociada a un ejemplar con representación de felino encontrado en río Matanzas, cerca de Cusi Cusi (Montenegro \& Ruiz 2007: 170). ${ }^{4}$

Horta et al. (2016) proponen denominar "Atacameño" a este grupo estilístico, atendiendo a su presencia tanto en San Pedro como en el Loa. Hay que señalar, sin embargo, que tabletas de esta clase son también frecuentes en la puna y el valle Calchaquí, a pesar de la menor cantidad de artefactos inhalatorios conocidos para el NOA. A ellos se suman los ejemplares analizados en este trabajo -del lote Calilegua y del Recinto 3- que son los primeros conocidos para el PDR I de la quebrada y sugieren que, por entonces, dicho estilo pudo ser relativamente común en esta región y tal vez en otras partes del NOA circunpuneño, teniendo en cuenta que se conocen muy pocos contextos funerarios que puedan ser fehacientemente ubicados antes del PDR II. Más aún, hay que recordar que, a excepción de algunas inhumaciones identificadas a través de rescates en el área urbana de Tilcara (Otero \& Rivolta 2015), no se conocen contextos funerarios de la segunda mitad del primer milenio para la Quebrada de Humahuaca, la puna o el río Grande de San Juan, extensas regiones que claramente participaron del consumo de alucinógenos después del 1000 DC. Por ahora no hay modo de saber si esta costumbre existía allí en el Formativo Tardío o el tipo de objetos que se empleaban. Teniendo en cuenta estos sesgos y vacíos en la información disponible, convendría evitar la asignación de grupos estilísticos a regiones o a colectivos sociales específicos.

En cuanto a las tabletas planiformes, la ausencia de diseños Tiwanaku permite ubicarlas con posterioridad al siglo x. Núñez (1976: 99) obtuvo una fecha 


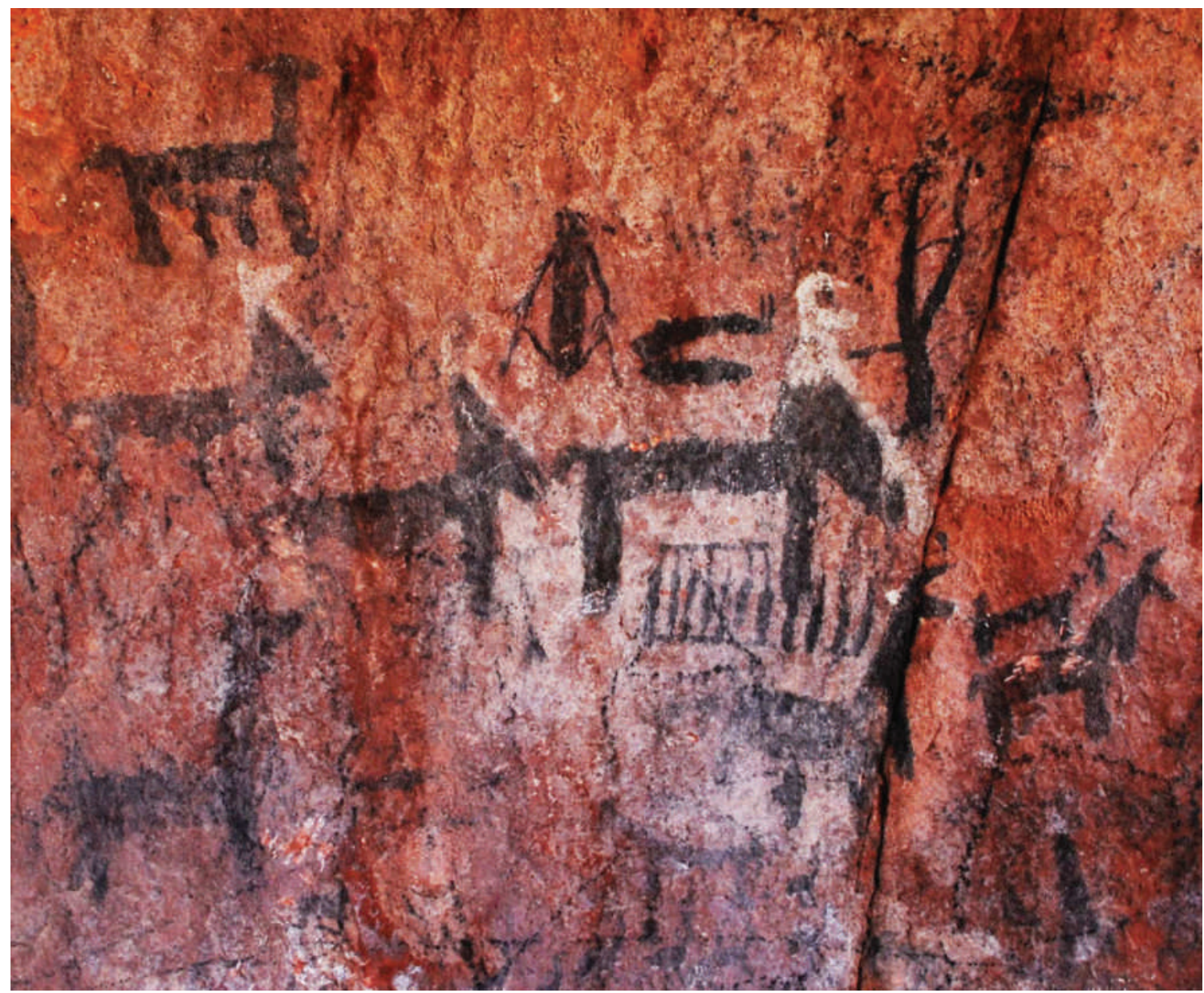

Figura 19. Mujer Heráldica en Inca Cueva 1. Figure 19. Mujer Heráldica in Inca Cueva 1.

radiocarbónica de $900 \pm 80$ años AP (I-1205) para una tumba de Quitor 9 (San Pedro de Atacama) que incluía una tableta con apéndice de felino y una planiforme con Mujer Heráldica, lo que confirma la coexistencia de ambos grupos estilísticos en la Fase Yaye (Tarragó 1989: 450-451), contemporánea del PDR I de la quebrada. Las representaciones de este último ícono (llamado "mujer grávida" por Tarragó 1989) son relativamente frecuentes por esta época en los oasis de Atacama, donde se conocen al menos siete ejemplares (Tarragó 1989, Laurencich-Minelli 2011). Torres (1987: 50) destaca la amplia difusión en Sudamérica de esta imagen femenina, que otros autores vinculan a Pachamama (Llagostera 1995) o Yayamama (Laurencich-Minelli 2011: 54). La presencia de un motivo similar en el arte rupestre de Inca Cueva 1 (Ashero 2000b: 32) indica que la Mujer Heráldica también formaba parte del mundo social de Humahuaca. Los diseños que la flanquean en Inca Cueva, un motivo de coito a su izquierda y un camélido amamantando la cría a su derecha, ciertamente avalan su identificación con los poderes genésicos de la tierra (fig. 19). Aschero (1979) asigna este motivo al grupo C1, correspondiente al Período Agroalfarero Tardío (sensu González \& Pérez 1972), señalando asociaciones con motivos abstractos propios del estilo alfarero Isla. $\mathrm{Si}$ a esto se suma la ausencia de tabletas planiformes entre la parafernalia de inhalar más tardía conocida para esta y otras regiones del NOA, cabe inferir que este grupo estilístico también estaba vigente en la quebrada durante el PDR I pero que, a diferencia del anterior, dejó de utilizarse posteriormente. Aunque circunstanciales, estas evidencias llevan a pensar que las tabletas planiformes del lote Calilegua son del PDR I, época en que coexistieron con las zoomorfas de un apéndice. 
El hallazgo de goteros en el Recinto 3 de Muyuna también ubica estos instrumentos en el PDR I y muestra que, junto a los equipos inhalatorios, formaban parte de un repertorio más amplio de implementos para el consumo de alucinógenos aparentemente manejados por las mismas personas o grupos domésticos. Como ya se mencionó, también la tumba NeA21 de La Isla contenía entre sus ofrendas un gotero e instrumentos de inhalar. Berenguer \& Acevedo (2015) mencionan asociaciones similares para Chiu Chiu (región del Loa) y Playa Miller-4, en la costa de Arica. La colección obtenida por Gerling a fines del siglo xix en un cementerio cercano a Santa Catalina (Lehmann-Nitsche 1902) incluye varios implementos de inhalar y por lo menos tres goteros, aunque no se sabe si fueron encontrados en los mismos contextos. Como aporte a la cartografía de estas asociaciones, cabe mencionar que el NMAI posee un conjunto de objetos procedentes de una tumba de Pisagua que incluye al menos un gotero y varios elementos del complejo inhalatorio, además de instrumentos de pesca y numerosas cuentas de collar (fig. 20). Estas evidencias avalan las propuestas sobre la existencia en tiempos prehispánicos de chamanes o curanderos especializados en el manejo de substancias de valor ritual/medicinal (Wassén 1972, Llagostera et al. 1988).

Se ha postulado también que estos chamanes/ curanderos tendrían estrechas relaciones con el tráfico caravanero y/o con el poder político (Llagostera et al. 1988, Palma 1993, Berenguer 1998, Montenegro \& Ruiz 2007). La asociación del complejo psicotrópico con bienes alóctonos (p. ej. conchas, cerámica exótica, la madera para confeccionar la parafernalia y las propias plantas consumidas) y artefactos vinculados a la carga de llamas (p. ej. "tarabitas") fundamentaría la primera idea, mientras que su presencia en tumbas con acompañamientos excepcionales por su cantidad o calidad (p. ej. metales preciosos) justificaría la segunda. En el lote Calilegua hay tarabitas, campanas de madera (¿cencerros?), bienes exóticos (cascabeles de nuez, vasijas Yavi/Chicha) y varias piezas de oro, pero es imposible saber si estaban asociadas a las tabletas o goteros. Los contextos excavados en Muyuna brindaron pocos objetos alóctonos, aunque las tumbas contenían varios artefactos de madera que no pudieron ser recuperados ni identificados. Por cierto, las evidencias mencionadas en la sección anterior muestran la importancia que tenía la ganadería para aquella comunidad, mientras que la presencia de la Mujer Heráldica en el santuario pastoril de Inca Cueva sugiere que ciertas deidades del mundo chamánico tenían también injerencia en el bienestar de los rebaños, pero estas no son referencias al tráfico caravanero, específicamente.

Lo que podría marcar una relación entre los habitantes del Recinto 3 y los viajes de larga distancia son las cuentas de ceniza volcánica y el mineral de cobre colocados junto a la cavidad donde asentaba el poste central de la casa (fig. 18). Ofrendas similares, incluyendo preformas y desechos de fabricación de las cuentas tanto blancas como verdes, han sido reiteradamente documentadas durante los últimos años a lo largo de rutas interregionales de los Andes circumpuneños, desde el desierto de Atacama hasta los valles orientales de Jujuy. Se encuentran sobre todo en puntos significativos del camino, como portezuelos o campamentos de pernocta, aunque también se encuentran en otros contextos, por ejemplo, cumbres de baja altura y manantiales (Pimentel 2009; Nielsen et al. 2017). Inicialmente se pensó que el cobre era lo importante de estas ofrendas que, por consiguiente, aludían a la metalurgia (Nielsen 1997: 361-364). Sin embargo, el análisis de cuentas y rocas verdes de estos contextos reveló que algunas no contienen metal, lo que sugiere que el color o el contraste de colores (allqa) podría ser uno de los principales atributos significantes de estas ofrendas. Esto explicaría que, en otros contextos o momentos, la ofrenda verde-blanca mantuviera su eficacia a pesar del reemplazo de las substancias, como sucede en los equipos de inhalar con incrustaciones de minerales de cobre y conchas o, en épocas más recientes, cuando las cuentas de vidrio reemplazan a la malaquita o crisocola en las ofrendas de ruta (Nielsen et al. 2017: 252). Esta conclusión encuentra eco en el testimonio del cura de Atacama la Baja, recogido por Horta et al. (2016: 94), quien en el siglo Xvir observaron en Caspana la costumbre de ofrecer "piedras de varios colores de pedernales y polvos de colores" a una antigua tableta de inhalar devenida ella misma en ídolo.

En cuanto a las relaciones entre alucinógenos y poder, los pocos datos disponibles para la quebrada a comienzos del segundo milenio son ambiguos. Si se consideran las piezas de oro en los ajuares funerarios como índices de la jerarquía del difunto o de sus deudos (p. ej. Tarragó et al. 2010), habría que concluir que los tres individuos inhumados en la tumba NeA21 de La Isla con parafernalia alucinógena y ocho piezas de oro, además de algunos elementos alóctonos (obsidiana), conjugaban el conocimiento chamánico con una elevada jerarquía. Los difuntos del Recinto 3 de 


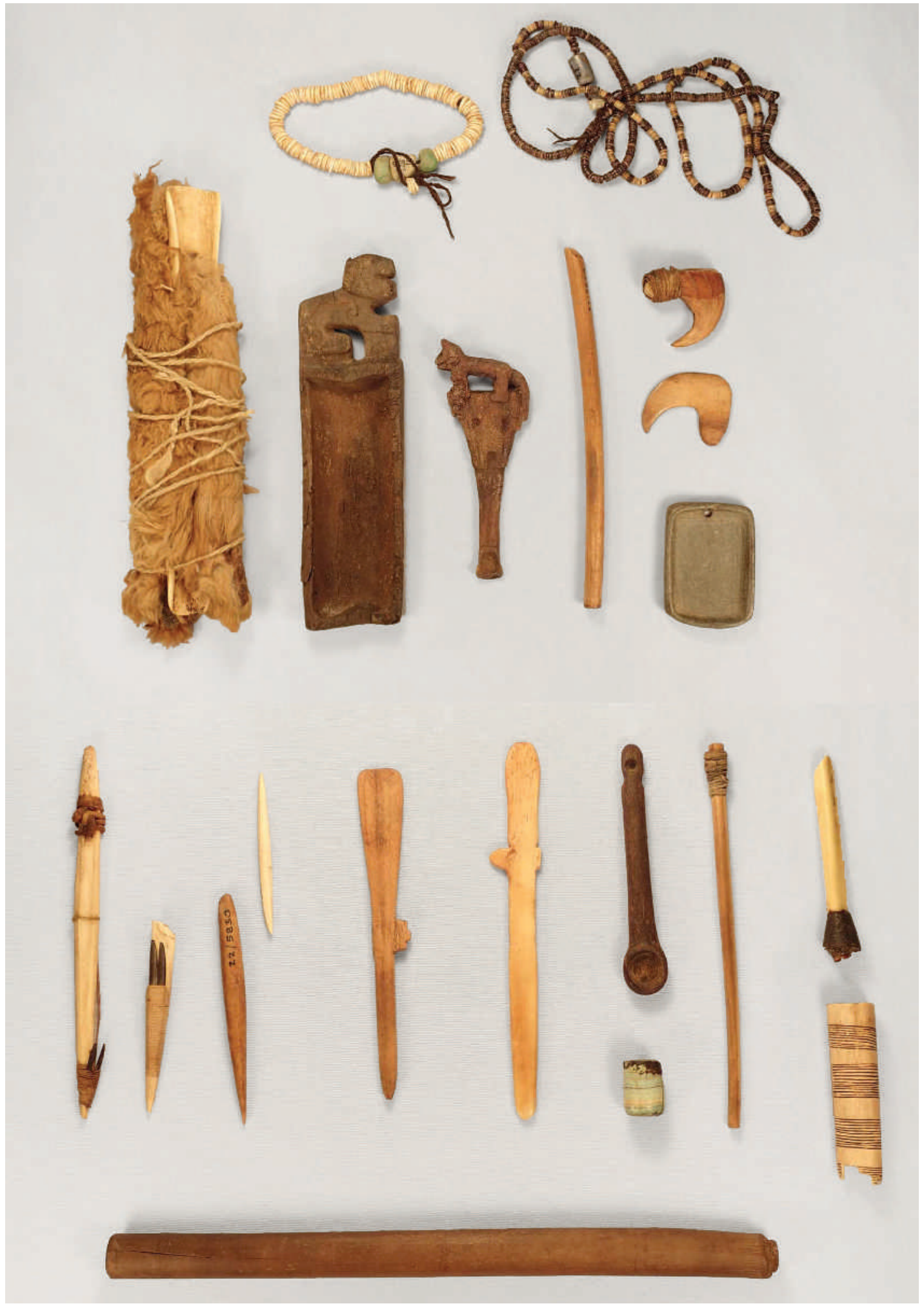

Figura 20. Conjunto funerario procedente de Pisagua (NMAI n ${ }^{\circ} 225830$ ). Figure 20. Funerary assenblage from Pisagua (NMAI $n^{\circ} 225830$ ). 
Muyuna, en cambio, carecían de tales riquezas y sus acompañamientos eran modestos, a pesar de su clara vinculación al consumo de substancias psicotrópicas. Por otra parte, el individuo de la tumba M11 de La Isla (Tarragó et al. 2010), la de mayor riqueza conocida en la región, tanto por sus 25 piezas de oro como por la cantidad total de objetos depositados, no contaba en su acompañamiento con evidencias claras de parafernalia alucinógena, más allá de dos tubos pequeños que no muestran las dimensiones ( $55 \mathrm{~mm}$ y $11 \mathrm{~mm}$ de largo) $\mathrm{ni}$ los atributos específicos de los implementos inhalatorios. Pero como señala Yacobaccio (2012), varios indicios lo vinculaban con el pastoreo y el tráfico, como dos illas de terracota, una tarabita, láminas de oro en forma de camélido, cuatro campanillas de bronce y seis de oro, además de otros bienes alóctonos (p. ej. un esqueleto de guacamayo, cerámica Yavi/Chicha), a lo que podrían agregarse las cinco cuentas de ceniza volcáncia y el mineral de cobre, que recuerdan las ofrendas de ruta discutidas anteriormente. Falta mucho para entender la sociedad del PDR I en la Quebrada de Humahuaca, pero estos contextos muestran, una vez más, que la relación entre formas de organización y lo que en arqueología se acostumbra llamar "bienes de prestigio" no obedece a generalizaciones simples, sino que requiere contextualizar históricamente el valor y eficacia social de los objetos y de las prácticas que los involucran.

\section{NOTAS}

${ }^{1}$ Menciona también "Boiquepara” (Bilcapara), un poblado que se encuentra en la Puna, donde realizaron excavaciones a fines de 1919 con Weiser.

${ }^{2} \mathrm{Si}$ bien, la mayoría de los números de inventario corresponden a objetos individuales, algunos de ellos abarcan varios objetos, como sucede a menudo con las cuentas de collar o los instrumentos de hueso, entre otros.

${ }^{3}$ Debenedetti (1912) fue uno de los primeros en proponer la existencia de vínculos entre la quebrada y Tiwanaku a partir de los vasos con cintura de la Isla y los equipos de inhalar, pero otros autores rechazaron su idea señalando que los primeros difieren de los keros altiplánicos en su forma y decoración, mientras que los segundos carecen de la iconografía característica y se parecen más a los atacameños (Boman 1923: 10, Bennett et al. 1948: 146).

${ }^{4}$ Esta datación se menciona como 1384 DC, pero en ninguna de las publicaciones que la referencian se brinda información sobre el laboratorio donde se realizó o su antigüedad radiocarbónica y desviación estándar.
Reconocimientos El estudio de las colecciones del NMAI se realizó gracias al apoyo de una post-doctoral fellowship de la Smithsonian Institution, Washington DC (2014-2015), a la hospitalidad de Ramiro Matos y Antonio Curet (mis advisers) y a la asistencia de su personal, en particular Victoria Cranner, Emily Kaplan, Isaac St. John, Tony Williams, Cali Martin y Rachel Menyuk. Estoy especialmente agradecido a Verónica Quiguango, no solo por su ayuda con las colecciones, sino, sobre todo, por confiarme algunas de sus experiencias conviviendo con los poderosos objetos que allí habitan. La correspondencia con José Berenguer fue importante para clarificar varios puntos aquí tratados. Guillermina Couso aportó información clave para reconstruir la vida de Schuel y Malena Vázquez me asistió en la confección de las figuras.

\section{REFERENCIAS}

Albarracín-Jordán, J., J. Capriles \& M. Miller. 2014. Transformations in ritual practice and social interaction on the Tiwanaku periphery. Antiquity 88: 851-862. Cambridge.

Ambrosetti, J. 1904. Apuntes sobre la arqueología de la Puna de Atacama. Revista del Museo de La Plata XII: 1-30. La Plata.

Ambrosetti, J. 1912. Resultados de las exploraciones arqueológicas en el pucará de Tilcara. Actas del XVII Congreso Internacional de Americanistas, pp. 497-498. Buenos Aires.

Annual Report. 1925. For the period from April 1, 1924, to April 1, 1925 of the Board of Trustees of the Museum of the American Indian-Heye Foundation presented to George G. Heye. <https://transcription.si.edu/view/8278/NMAI001_404_03_001-000001> [Consultado 26-02-2018].

Aschero, C. 1979. Aportes al estudio del arte rupestre de Inca Cueva 1 (Departamento de Humahuaca, Jujuy). Actas de las Jornadas de Arqueología del Noroeste Argentino, pp. 419-459. Buenos Aires: Universidad del Salvador.

Aschero, C. 2000a. El poblamiento del territorio. En Nueva historia argentina, vol. I, pp. 17-59. Buenos Aires: Sudamericana.

Aschero, C. 2000b. Figuras humanas, camélidos y espacio en la interacción circumpuneña. En Arte en las rocas: arte rupestre, menhires y piedras de colores en Argentina, M. Podestá \& M. de Hoyos, Eds., pp. 15-44. Buenos Aires: Sociedad Argentina de Antropología y Asociación Amigos del INAPL.

Balesta, B. \& N. Zagorodny. 2000. Memorias e intimidades de una colección arqueológica. Relaciones 25: 41-50. Buenos Aires.

Bennett, W., E. Bleiler \& F. Sommer. 1948. Northwest argentine archaeology. New Haven: Yale University Publications in Anthropology-Yale University Press.

Berenguer, J. 1998. La iconografía del poder en Tiwanaku y su rol en la integración de zonas de frontera. Boletín del Museo Chileno de Arte Precolombino 7: 19-37. Santiago. 
Berenguer, J. \& N. Acevedo. 2015. Tubos de hueso de ave como implementos chamánicos en el desierto de Atacama, Siglos XI-Xv. Boletín del Museo Chileno de Arte Precolombino 20: 51-72. Santiago.

Berenguer, J., A. Deza, A. Román \& A. Llagostera. 1986. La secuencia de Myriam Tarragó para San Pedro de Atacama: un test por termoluminiscencia. Revista Chilena de Antropología 5: 17-54. Santiago.

Boman, E. 1923. Los ensayos para establecer una cronología prehispánica en la región Diaguita (República Argentina). Boletín de la Academia Nacional de la Historia, vol. vi, pp. 1-31. Quito.

Casanova, E. 1942. El yacimiento arqueológico de Angosto Chico. Relaciones III: 73-87. Buenos Aires.

Cigliano, E. 1967. Investigaciones antropológicas en el Yacimiento de Juella (Dep. de Tilcara, Provincia de Jujuy). Revista del Museo de La Plata (NS), Sección Antropología vi: 123-249. La Plata.

Debenedetti, S. 1910. Exploración arqueológica en los cementerios prehistóricos de la Isla de Tilcara (quebrada de Humahuaca, prov. de Jujuy). Publicaciones de la sección antropológica de la Facultad de Filosofía y Letras, nº 6. Buenos Aires: Facultad de Filosofía y Letras, UBA.

Debenedetti, S. 1912. Influencias de la Cultura de Tiahuanaco en la región del Noroeste Argentino (nota preliminar). Publicaciones de la Sección Antropológica 11: 5-27. Buenos Aires: Facultad de Filosofía y Letras, ubA.

Debenedetti, S. 1918. La XVI a expedición arqueológica de la Facultad de Filosofía y Letras. Physis Iv: 196-207. Buenos Aires.

Farro, M., S. García \& A. Martínez. 2012. Expediciones, colecciones y formas de registro. La colección arqueológica Benjamín Muniz Barreto. En Los secretos de Barba Azul: fantasías y realidades de los archivos del Museo de La Plata, T. Kelly \& I. Podgorny, Eds., pp. 139-190. Rosario: Prohistoria.

González, A. \& J. Pérez. 1972. Argentina indígena, vísperas de la conquista. Buenos Aires: Paidós.

Hernández Llosas, M. 2000. Quebradas altas de Humahuaca a través del tiempo: el caso Pintoscayoc. Estudios Sociales del NOA 4 (2): 167-224. Jujuy.

Horta, H. 2012. El estilo circumpuneño en el arte de la parafernalia alucinógena prehispánica (Atacama y Noroeste Argentino). Estudios Atacameños 43: 5-34. San Pedro de Atacama.

Horta, H., J. Hidalgo \& V. Figueroa. 2016. Transformación y resignificación de la parafernalia alucinógena prehispánica en Atacama a la luz de un documento del siglo XVII. Estudios atacameños 53: 93-116. San Pedro de Atacama.

Ibáñez-Novión, M. 1970. La Prensa, 5 de abril. Buenos Aires.

Krapovickas, P., 1961. Algunos materiales de Tilcara, pertenecientes a la Colección Schuel del Museo de La Plata. Revista del Instituto de Antropología I: 249-269. Rosario.
LaUrencich-Minelli, L. 2011. Ofrendas atacameñas en la colección de Monseñor Campagner (Treviso, Italia). Estudios Atacameños 41: 45-62. San Pedro de Atacama.

Lehmann-Nitsche, R. 1902. Catálogo de las antigüedades de la provincia de Jujuy. Revista del Museo de La Plata 11: 75-120. La PLata.

Lechtman, H., P. Cruz, A. Macfarlane \& S. Carter. 2010. Procesamiento de metales durante el horizonte medio en el altiplano surandino (Escaramayu, Pulacayo, Potosí, Bolivia). Boletín del Museo Chileno de Arte Precolombino 15 (2): 9-27. Santiago.

Llagostera, A. 1995. Art in the snuff trays of San Pedro de Atacama (northern Chile). En Andean art: visual expression and its relation to andean beliefs and values, P. Dransart, Ed., pp. 51-77. Aldershot: Avebury.

Llagostera, A., C. Torres \& M. Costa. 1988. El complejo psicotrópico en Solcor-3 (San Pedro de Atacama). Estudios atacameños 9: 67-106. San Pedro de Atacama.

Madrazo, G. 1969. Reapertura de la investigación en Alfarcito (Pcia. de Jujuy, Rep. Argentina). Olavarría: Museo Etnográfico Municipal "Damaso Arce".

MAYER, E. 1986. Armas y herramientas de metal prehispánicas en Argentina y Chile. Munich: $\mathrm{CH}$ Beck.

Mazza, S. \& N. Álvarez. 1929. Museo Arqueológico Provincial de Jujuy. La personalidad de su fundador Carlos Schuel. Congreso de Patología Regional del Norte 5 (2): 1415-1430.

Mercoli, P., D. Olivera \& A. Nielsen. 2014. La explotación de camélidos en la Quebrada de Humahuaca a comienzos del Período Tardío: el caso de Muyuna. Cuadernos del Instituto Nacional de Antropología y Pensamiento LatinoamericanoSeries Especiales (1) 2: 24-43. Buenos Aires.

Montenegro, M. \& M. Ruiz. 2007. Tránsito y paisaje en la Puna de Jujuy durante los Desarrollos Regionales: una aproximación iconográfica. Cuadernos FHYCS-UNJU 32:167-185. Jujuy.

Nielsen, A. 1997. El tráfico caravanero visto desde la Jara. Estudios Atacameños 14: 339-371. San Pedro de Atacama.

Nielsen, A. 2001. Evolución social en Quebrada de Humahuaca (AD 700-1536). En Historia argentina prehispánica, E. Berberián \& A. Nielsen, Eds., vol. I, pp. 171-264. Córdoba: Brujas.

Nielsen, A. 2006. Plazas para los antepasados: descentralización y poder corporativo en las formaciones políticas preincaicas de los Andes circumpuneños. Estudios Atacameños 31: 63-89. San Pedro de Atacama.

Nielsen, A. 2007. El Período de Desarrollos Regionales en la Quebrada de Humahuaca: aspectos cronológicos. En Sociedades precolombinas surandinas: temporalidad, interacción y dinámica cultural del NOA en el ámbito de los Andes centro-sur, V. Williams, B. Ventura, A. Callegari \& H. Yacobaccio, Eds., pp. 235-250. Buenos Aires: Taller Internacional de Arqueología del NOA y Andes Centro Sur.

Nielsen, A., C. Angiorama \& F. Ávila. 2017. Ritual as interaction with non-humans: Pre-Hispanic mountain 
pass shrines in the Southern Andes. En Rituals of the Past. Prehispanic and Colonial Case Studies in Andean Archaeology, S. Rosenfeld \& S. Bautista, Eds., pp. 241-266. Boulder: University Press of Colorado.

NúÑEZ, V. 1974. Conceptos instrumentales y marco teórico en relación al análisis del desarrollo cultural del Noroeste Argentino. Revista del Instituto de Antropología v: 169190. Córdoba.

NúÑEZ, L. 1976. Registro regional de fechas radiocarbónicas del norte de Chile. Estudios Atacameños 4: 74-123. San Pedro de Atacama.

Ortiz, G., C. Heit Lanart, L. Nieva, F. Zamora, N. Batallanos \& F. Chapur. 2015. Pensando al Formativo desde la región pedemontana de las Yungas de Jujuy. En Crónicas materiales precolombinas: arqueología de los primeros poblados del Noroeste Argentino, M. A. Korstanje, M. Lazzari, M. Basile, F. Bugliani, V. Lema, L. Pereyra Domingorena \& M. Quesada, Eds., pp. 695-720. Buenos Aires: Sociedad Argentina de Antropología.

Otero, C. \& C. Rivolta. 2015. Nuevas interpretaciones para la secuencia de ocupación de Tilcara (Quebrada de Humahuaca, Jujuy). Intersecciones en Antropología 16: 145-159. Buenos Aires.

Palma, J. 1993. Aproximación al estudio de una sociedad compleja: un análisis orientado en la funebria. Arqueología 3: 41-68. Buenos Aires.

Pelissero, N. 1995. El sitio arqueológico de Keta-Kara. Buenos Aires: Centro Argentino de Etnología Americana.

PÉREZ, J., 1973. Arqueología de las culturas agroalfareras de la Quebrada de Humahuaca (Provincia de Jujuy, República Argentina). América Indígena xxxiII: 667-678. Ciudad de México.

Pérez, J. \& I. Gordillo. 1993. Alucinógenos y sociedades indígenas del noroeste argentino. Anales de Antropología 30: 299-350. Ciudad de México.

Pimentel, G. 2009. Las huacas del tráfico. Arquitectura ceremonial en rutas prehispánicas del desierto de Atacama. Boletín del Museo Chileno de Arte Precolombino 14 (2): 9-38. Santiago.

Richardin, P., C. Lavier, H. Horta, V. Figueroa \& N. Lira. 2015. Radiocarbon dating of Atacama (Chile) snuff trays: an update on stylistic and chronological correlations. $R a$ diocarbon 57: 775-784.

Rivolta, M. \& A. Nielsen. 1998. La Falda: un cementerio hispano-indígena en Tilcara. Palimpsesto 5: 173-182. Santiago.

SAlas, A. 1945. El antigal de Ciénaga Grande (quebrada de Purmamarca, Provincia de Jujuy). Buenos Aires: Publicaciones de la Facultad de Filosofía y Letras, UBA.

Schuel, K. 1919-1920. Diarios de campo de las expediciones Muñiz Barreto: I (17/8/1919 al 31/12/1919, pp. 1-52) y II (25/3/1920 al 20/10/1920, pp. 52-87). Transcripción mecanografiada en archivo, Museo de la Plata.
Schuel, K. 1929. Ruinas de las poblaciones de los indígenas de la Provincia de Jujuy. Congreso de Patología Regional del Norte 5 (2): 1430-1451.

SELDES, V. 2006. Bioarqueología de poblaciones prehistóricas de la quebrada de Humahuaca (Jujuy, Argentina). Estudios atacameños 31: 47-61. San Pedro de Atacama.

Sprovieri, M. 2009. Alucinaciones en circulación. Una mirada a la interacción surandina tardía desde las tabletas y tubos de La Paya (valle Calchaquí, Salta). Anales de Arqueología y Etnología 63-64: 81-105. Cuyo.

TArragó, M. 1977. Relaciones prehispánicas entre San Pedro de Atacama (norte de Chile) y regiones aledañas: la Quebrada de Humahuaca. Estudios Atacameños 5: 50-63. San Pedro de Atacama.

TARRAgó, M. 1989. Contribución al conocimiento arqueológico de las poblaciones de los oasis de San Pedro de Atacama en relación con los otros pueblos puneños, en especial, el sector septentrional del valle Calchaquí. Tesis para optar al grado de Doctora en Historia con especialidad en Antropología, Facultad de Hmanidades y Artes, Universidad Nacional de Rosario, Argentina.

Tarragó, M., L. González, G. Ávalos \& M. Lamamí. 2010. Oro de los señores. La tumba 11 de la isla de Tilcara (Jujuy, Noroeste Argentino). Boletín del Museo Chileno de Arte Precolombino 15: 47-63. Santiago.

Torres, C. 1987. The iconography of south american snuff trays and related paraphernalia. Göteborg: Göteborgs Etnografiska Museum.

Torres, C. 1998. Psychoactive substances in the archaeology of northern Chile and north-western Argentina. Chungara 30: 49-63. Arica.

WASsÉN, H. 1972. A medicine man's implements and plants in a Tiahuanaco tomb in highland Bolivia. Göteborg: Göteborgs Etnografiska Museum.

YACовACсIO, H. 2012. Intercambio y caravanas de llamas en el sur andino (3000-1000 AP). Comechingonia 16: 31-51. Córdoba.

Zaburlín, M. 2009. Historia de ocupación del pucará de Tilcara: Jujuy, Argentina. Intersecciones en Antropología 10 (1): 89-103. Buenos Aires. 